\title{
A compendium answering over 140 questions on COVID-19 and SARS-CoV-2
}

CARMEN RIGGIONI ${ }^{1}$, Pasquale Comberiati ${ }^{2}$, Mattia Giovannini ${ }^{3}$, Ioana Agache $^{4}$, Mubeccel Akdis ${ }^{5}$, Magna Alves-Correia ${ }^{6}$, Josep Anto ${ }^{7}$, Alessandra Arcolaci ${ }^{8}$, Ahmet Azkur $^{9}$, Dilek Azkur ${ }^{10}$, Burcin Beken ${ }^{11}$, Cristina Boccabella ${ }^{12}$, Jean Bousquet ${ }^{13}$, Heimo Breiteneder $^{14}$, Daniela Carvalho ${ }^{15}$, Leticia De las Vecillas ${ }^{16}$, Zuzana Diamant ${ }^{17}$, Ibon Eguiluz-Gracia $^{18}$, Thomas Eiwegger ${ }^{19}$, Stefanie Eyerich ${ }^{20}$, Wytske Fokkens ${ }^{21}$, Ya-dong $\mathrm{GaO}^{22}$, Farah Hannachi ${ }^{23}$, Sebastian Johnston ${ }^{24}$, Marek Jutel ${ }^{25}$, Aspasia Karavelia ${ }^{26}$, Ludger Klimek $^{27}$, Beatriz Moya ${ }^{28}$, Kari Nadeau ${ }^{29}$, Robin O'Hehir ${ }^{30}$, Liam O’Mahony ${ }^{31}$, Oliver Pfaar ${ }^{32}$, Marek Sanak ${ }^{33}$, Jürgen Schwarze ${ }^{34}$, Milena Sokolowska ${ }^{35}$, María José Torres $^{36}$, Willem Van de Veen ${ }^{37}$, Menno van Zelm ${ }^{30}$, De Yun Wang ${ }^{38}$, Luo Zhang ${ }^{39}$, Rodrigo Jimenez-Saiz ${ }^{40}$, and Cezmi Akdis ${ }^{37}$

${ }^{1}$ Hospital Sant Joan de Déu

${ }^{2}$ University of Verona

${ }^{3}$ Anna Meyer Chidren's University Hospital

${ }^{4}$ Transylvania University of Brasov

${ }^{5}$ University of Zürich

${ }^{6}$ University of Porto

${ }^{7}$ ISGLoBAL

${ }^{8}$ Borgo Roma Hospital

${ }^{9}$ Kirikkale Universitesi Veteriner Fakultesi

${ }^{10}$ Kirikkale University Faculty of Medicine

${ }^{11}$ Trakya University Faculty of Medicine

${ }^{12}$ Catholic University of the Sacred Heart Rome Campus

${ }^{13}$ Université Versailles, St-Quentin-en-Yvelines

${ }^{14}$ Medical University of Vienna

${ }^{15}$ University of Lisbon

${ }^{16}$ Hospital Universitario Marques de Valdecilla

${ }^{17}$ Institute for Clinical Science, Skane University Hospital

${ }^{18}$ IBIMA-Regional University Hospital of Málaga, UMA, Malaga

${ }^{19}$ The Hospital for Sick Children

${ }^{20}$ Technical University and Helmholtz Center Munich

${ }^{21}$ University of Amsterdam

${ }^{22}$ Wuhan University Zhongnan Hospital

${ }^{23}$ Hospital Centre of Luxembourg

${ }^{24}$ Imperial College London

${ }^{25}$ Wroclaw Medical University

${ }^{26}$ General Hopsital of Chania

${ }^{27}$ Zentrum für Rhinologie und Allergologie 
${ }^{28}$ Hospital Universitario 12 de Octubre

${ }^{29}$ Stanford University

${ }^{30}$ Monash University

${ }^{31}$ University College Cork National University of Ireland

32 University Hospital Marburg, Philipps-Universität Marburg, Marburg, Germany.

${ }^{33}$ Jagiellonian University Medical College

${ }^{34}$ University of Edinburgh, Edinburgh

${ }^{35}$ Swiss Institute of Allergy and Asthma Research, University of Zurich

${ }^{36}$ Universidad de Málaga Facultad de Medicina

${ }^{37}$ University of Zurich

${ }^{38}$ Yong Loo Lin School of Medicine, National University of Singapore

${ }^{39}$ Beijing TongRen Hospital, Capital Medical University,

${ }^{40}$ National Centre for Biotechnology

May 29, 2020

\begin{abstract}
In December 2019, China reported the first cases of the coronavirus disease 2019 (COVID-19). This disease, caused by the severe acute respiratory syndrome-related coronavirus 2 (SARS-CoV-2), has developed into a pandemic. To date it has resulted in $\sim 5.6$ million confirmed cases and caused 353,334 related deaths worldwide. Unequivocally, the COVID-19 pandemic is the gravest health and socio-economic crisis of our time. In this context, numerous questions have emerged in demand of basic scientific information and evidence-based medical advice on SARS-CoV-2 and COVID-19. Although the majority of the patients show a very mild, self-limiting viral respiratory disease, many clinical manifestations in severe patients are unique to COVID-19, such as severe lymphopenia and eosinopenia, extensive pneumonia, a "cytokine storm" leading to acute respiratory distress syndrome, endothelitis, thrombo-embolic complications and multiorgan failure. The epidemiologic features of COVID-19 are distinctive and have changed throughout the pandemic. Vaccine and drug development studies and clinical trials are rapidly growing at an unprecedented speed. However, basic and clinical research on COVID-19-related topics should be based on more coordinated high-quality studies. This paper answers pressing questions, formulated by young clinicians and scientists, on SARS-CoV-2, COVID-19 and allergy, focusing on the following topics: virology, immunology, diagnosis, management of patients with allergic disease and asthma, treatment, clinical trials, drug discovery, vaccine development and epidemiology. Over 140 questions were answered by experts in the field providing a comprehensive and practical overview of COVID-19 and allergic disease.
\end{abstract}

\begin{tabular}{ll}
\hline Table of contents & Page \\
\hline Introduction & 7 \\
1. SARS-CoV-2 virology & 7 \\
2. Immunology of COVID-19 & 9 \\
2.1 B cell and antibody responses & 9 \\
2.2. Type 2 responses and eosinophils & 11 \\
2.3. T cells and lymphopenia & 12 \\
2.4 Immunopathology, immunosuppression & 14 \\
and immune regulation & \\
3. Diagnosis of COVID-19 & 16 \\
4. Organization of allergy outpatient clinics & 18 \\
and laboratories during the COVID-19 & \\
pandemic & \\
5. COVID-19 and allergic disease & 20 \\
5.1 Allergic rhinoconjunctivitis & 20
\end{tabular}




\begin{tabular}{ll}
\hline Table of contents & Page \\
\hline 5.2 Chronic rhinosinusitis and other upper & 21 \\
respiratory tract diseases & \\
5.3 Asthma & 23 \\
5.4 Atopic dermatitis and other skin lesions & 25 \\
5.5 Drug hypersensitivity & 26 \\
5.6 Handling of allergen immunotherapy & 26 \\
(AIT) during the COVID-19 pandemic & \\
6. Treatment of COVID-19 & 27 \\
7. Clinical trials and drug discovery in & 29 \\
COVID-19 & 32 \\
8. Vaccine development for COVID-19 & 33 \\
9. Epidemiology of COVID-19 and & \\
environmental factors & 38 \\
Conclusion & 50 \\
References &
\end{tabular}

\section{Main text}

\section{Introduction}

The first cases of the coronavirus disease 2019 (COVID-19), caused by the novel severe acute respiratory syndrome-related coronavirus 2 (SARS-CoV-2), were reported in China in December $2019^{1}$ and rapidly led to pandemic. Currently, around 5.6 million confirmed cases of COVID-19 and 353,334 COVID-19-related deaths have been reported globally. ${ }^{2}$ These numbers, which are still rising, likely underestimate the cumulative incidence of COVID-19 due to several factors; these include limitations of current diagnostic tests, the extent of population testing and reporting, and the type and timing of community mitigation strategies adopted by each country, among others. ${ }^{3}$ COVID-19 shows a complex clinical profile with many different presentations. Like in many other viral infections, subclinical, mild, moderate, or severe cases (10-20\% of patients require hospitalization and $2-4 \%$ intensive care unit, ICU) presenting with or without pneumonia are observed. Asymptomatic cases are common but, to date, there is a lack of epidemiological surveys that provide a clear percentage of asymptomatic cases. ${ }^{4,5}$

The COVID-19 pandemic is the world's gravest public health crisis of the 21st century, and there is an urgent need for reliable and updated scientific and clinical information. COVID-19 is a zoonosis that has now spread worldwide, and it will be practically impossible to eradicate the SARS-CoV-2 virus without vaccination. The main question will be to learn how to cope with this virus, as COVID-19 is becoming an important reason for morbidity and mortality in many countries. The aim of this paper is to provide short answers to pressing questions on epidemiology, virology, immunology, diagnostics, and treatment as well as optimal management of allergic diseases during the COVID-19 pandemic. These 144 answers are provided by a group of expert scientists and physicians, mainly from EAACI, and are grouped in 9 sections. All the information will be updated in the light of new upcoming evidence.

\section{Section 1: SARS-CoV-2 virology}

What is known about the origin of SARS-CoV-2?

The coronavirus family has caused zoonotic diseases such the Middle East Respiratory Syndrome (MERS). While a direct ancestor of SARS-CoV-2 is unknown, it is closely related to $\beta$-coronaviruses in bats and pangolins, which are likely its original reservoir. SARS-CoV-2 could have risen by selection in the animal host followed by zoonotic transfer and acquisition of further mutations in humans. It is possible that, during undetected human-to-human transmission, the virus mutated, optimizing the binding of its spike protein to 
human angiotensin-converting enzyme 2 (ACE2). Importantly, available SARS-CoV-2 genetic data do not evince an intentional human manipulation of the virus. ${ }^{6}$

What are the strains of SARS-CoV-2?

Three SARS-CoV-2 variants have been identified (A, B, and C), which differ in their amino acid sequences. The ancestral type $\mathrm{A}$ and the mutated type $\mathrm{C}$ are found in significant proportions outside East Asia, mainly in Europe and in the USA. Type B, which has mutated and spread, is the most common strain in East Asia. ${ }^{7}$ Continuous genome sequencing of virus mutations is needed to monitor the pandemic.

What are the receptors used by SARS-CoV-2 for cell entry?

SARS-CoV-2 binds to ACE2 via its spike protein to enter human cells ${ }^{8}$. Cell entry is facilitated by the host serine protease TMPRSS2 that cleaves the spike protein into S1 and S2 fragments, thus enabling cellular membrane fusion (Figure 1 ). ${ }^{9}$ ACE2 is highly expressed in the lungs, small intestine, kidney and heart, but not in innate and adaptive immune cells. ${ }^{10-13}$ SARS-CoV-2 also binds to CD147 (known as basigin or extracellular matrix metalloproteinase inducer), which is expressed in human airway and kidney epithelium, as well as in innate cells and lymphocytes ${ }^{14}$. Receptors reported for other coronaviruses, such as CD26, aminopeptidase $\mathrm{N}$ and glutamyl aminopeptidase could be utilized by SARS-CoV-2 for cell invasion. ${ }^{13,15,16}$

Are there ACE2 polymorphisms that affect COVID-19 severity?

There is limited evidence about COVID-19-associated polymorphisms. ACE might be one of the candidate genes that influences pneumonia progression in SARS. It is conceivable that the D allele influences the renin-angiotensin system via elevation of serum or local ACE levels, which may damage the endothelium or epithelium of the lungs. ${ }^{17}$ The variance in COVID-19 prevalence and mortality cannot be explained by an $\mathrm{ACE}$ insertion or deletion polymorphism alone, or one polymorphism of any single gene. However, polymorphisms in genes of toll-like receptors, inflammasome, intracellular molecular sensors, interferons $(\mathrm{IFNs})^{18}$ and interleukins (ILs) may contribute.

What are the main SARS-CoV-2 molecules eliciting the immune response?

Structural proteins of SARS-CoV-2 virions, such as the spike glycoprotein, envelope, membrane and nucleocapsid, are the main immunogenic molecules (Figure 1) ${ }^{19,20}$ SARS-CoV-2 adaptive responses develop mainly to the spike protein, and immunodominant $\mathrm{T}$ and $\mathrm{B}$ cell epitopes have been reported. ${ }^{21}$ Intracellularly, the viral RNA replicase complex, and non-structural and translated proteins, activate innate immune pathways. This leads to an IFN type I response, NF-kB activation in epithelial cells, as well as activation of NLRP3 and other inflammasomes, in macrophages and dendritic cells. ${ }^{20}$

What are the main structural differences of SARS-CoV-1 and -2 ?

The spike protein of SARS-CoV-2 has a receptor-binding domain that binds ACE2 with higher affinity than SARS-CoV. ${ }^{8}$ In addition, the SARS-CoV-2 spike protein harbors a polybasic furin cleavage site (PRRAR) with an insertion of 4 amino acid residues, which is distinct from that found in SARS-CoV and other SARSlike viruses. This allows effective cleavage by furin and other proteases and determines viral infectivity and host range. ${ }^{6}$

Are there any similarities in the immune response to human immunodeficiency virus (HIV) and SARS-CoV2?

The severe lymphopenia observed in COVID- $19^{22}$ is similar to that reported in HIV infection and acquired immune deficiency syndrome. The latter is characterized by CD4+ T cell lymphopenia, whereas COVID-19 causes general lymphopenia. However, severe lymphopenia development in COVID-19 happens in weeks, whereas HIV-induced lymphopenia takes years. ${ }^{23}$ HIV and SARS-CoV-2 are RNA viruses and follow similar replication pathways; hence some RNA replication drugs may work in both diseases. ${ }^{24}$

Is the generation of mutated and more pathogenic strains of SARS-CoV-2 expected? 
There are 2 strains of SARS-CoV-2 that are clinically relevant. Genome analysis of SARS-CoV-2 from human samples shows high rates of mutation and deletion in several viral genes, including the spike-glycoprotein gene. ${ }^{25}$ COVID-19 treatments, including future vaccination against SARS-CoV-2, may drive the genetic evolution of the virus affecting virulence and pathogenicity. For example, a report on a 382-nt deletion in ORF8 of SARS-CoV2 isolated from patients in Singapore implied that mutations may arise as a result of human adaptation and could be associated with attenuation. ${ }^{26}$ Nevertheless, the emergence of a SARS-CoV-3 is possible as long as there is close contact between humans and living animals that harbor coronaviruses.

For how long is SARS-CoV-2 detected in oral and respiratory secretions from COVID-19 patients?

Data from 96 COVID-19 patients in China show SARS-CoV-2 detection in respiratory samples for a median of 18 days (13-29 days). In this study, sputum and saliva were not analyzed separately. Viral shedding was significantly longer in patients with severe disease, with a median of 21 days (14-30 days), compared to mild disease, 14 days (10-21 days). Furthermore, glucocorticoids treatment longer than 10 days significantly extended the duration of SARS-CoV-2 shedding. ${ }^{27}$ Viral load differed significantly by sample type, with respiratory samples showing the highest, followed by stool samples, and serum samples showing the lowest. ${ }^{27}$ Viral load range from $1.34 \times 10^{11}$ copies per $\mathrm{mL}$ to $7.52 \times 10^{5}$ in sputum of patients who died or survived, respectively. ${ }^{28}$

What is the relevance of the fecal-oral route in SARS-CoV-2 transmission?

SARS-CoV-2 infects gastrointestinal ACE2-expressing epithelial cells causing diarrhea in adults and children. It is frequently found in stool samples by reverse transcription polymerase chain reaction (RT-PCR) (Figure 2 ). Importantly, replicating SARS-CoV-2 has been isolated from stool. The median duration of the virus in stool samples (22 days, interquartile range 17-31 days) was significantly longer than in respiratory samples (18 days, 13-29 days. ${ }^{27}$ Thus, fecal transmission of SARS-CoV-2 is possible and might contribute to the spreading of COVID-19. ${ }^{29,30}$

\section{Section 2: Immunology of COVID-19}

\section{$2.1 \mathrm{~B}$ cell and antibody responses}

What is the time of seroconversion and duration of IgM and IgG responses against SARS-CoV-2?

From previous SARS studies, it is known that the median seroconversion time for detectable IgG was 17 days after infection. ${ }^{31}$ Detectable levels of SARS-specific IgG and neutralizing antibodies persisted for up to 720 days. This suggests that there is antibody-mediated protection from SARS-CoV recurrent infection for up to 2 years. $^{32}$ There are inconsistent reports on the humoral response to SARS-CoV-2. One study with 285 COVID-19 patients reported that SARS-CoV-2 virus-specific IgG and IgM peaked 17-19 days and 20-22 days after symptom onset, respectively. ${ }^{33}$ On the other hand, another study of 26 hospitalized COVID-19 patients showed that seroconversion could take up to 50 days. ${ }^{34}$ These discrepancies may be related to the time of SARS-CoV-2 diagnosis or the clinical characteristics of each cohort and warrant additional studies.

Are there differences in the SARS-CoV-2 antibody response between asymptomatic and symptomatic patients?

Preliminary findings indicate that asymptomatic and mild cases of COVID-19 can generate detectable levels of SARS-CoV-2-specific antibodies in serum. However, seroconversion is observed less frequently in asymptomatic compared to mild or severe cases, and many asymptomatic cases yield undetectable SARSCoV-2-specific antibody responses. ${ }^{33,35-37}$ So far, no robust data are available on the qualitative differences in humoral responses between asymptomatic and symptomatic COVID-19 patients.

Children tend to have mild forms of COVID-19, what is known about the specificity and affinity of their SARS-CoV-2 antibody response?

It is not clear which molecular mechanisms underlie the milder symptoms of COVID-19 in children as compared to adults. Children may mount a SARS-CoV-2 antibody response characterized by more efficient 
production of the so-called natural antibodies, which arise from activated IgM+ memory B cells. ${ }^{38}$ These cells, which are more prevalent in children than in adults, presumably produce broadly neutralizing antibodies early during the infection. Young children also frequently carry other respiratory viruses, which potentially limit SARS-CoV-2 infection, as reported for other viral infections. ${ }^{39}$ Differences between children and adults in the regulation of ACE2 expression may also play a role. ${ }^{38}$ ACE2 mRNA expression was high in type I and II alveolar epithelial cells, in nasal and oral mucosa and nasopharynx, in smooth muscle cells and endothelium of vessels from the stomach, small intestine, colon, and in the kidney of human adults (mean age 52+-22). ${ }^{40}$ Interestingly, a recent study demonstrated age-dependent ACE2 gene expression in the nasal epithelium, which was lowest in younger children and increased with age ${ }^{41}$ In addition, CD147, CD26 and their molecular interaction proteins seem to be differently expressed in peripheral blood mononuclear cells and $\mathrm{T}$ cells in children in comparison with adults. ${ }^{14}$

The generation of B-cell memory contributes to long-term immunity. Has the extent and quality of SARSCoV-2 memory responses been evaluated?

B cell receptor-sequencing has been conducted in the blood of COVID-19 patients. Naive B cells exhibited little clonal expansion, whereas CD27+CD38+ memory B cells showed the highest expansion levels among diverse B cell subsets. COVID-19 patients had significantly expanded specific B-cell receptor clones compared to those in the healthy controls. These findings suggest that B cells experience unique clonal variable, diversity, and joining gene segment rearrangements upon SARS-CoV-2 infection. ${ }^{42}$ The lifespan and functionality of these B cells remain to be elucidated.

Is the immunity acquired during the first COVID-19 wave enough for "herd immunity"?

The term "herd immunity" refers to the generation of population immunity that protects a region, or country, from infection. The number of confirmed COVID-19 cases has reached approximately 5.6 million. $^{2}$ The world population is estimated to be 7.8 billion. To ascertain the extent of herd immunity, it is pivotal to define the prevalence of SARS-CoV-2-exposed humans. It is thought that $60 \%$ is the minimum percentage of symptomatic or asymptomatic COVID-19 population required for herd immunity. That is to say that worldwide herd immunity may occur when 5 billion humans have a protective immune response against SARS-CoV-2. To date, there are no reliable data, particularly on the number of asymptomatic individuals that show seroconversion, to determine the degree of herd immunity. ${ }^{43}$

Given the role of IL-4 in immunoglobulin class-switching and germinal center reactions, could IL-4 axistargeting treatments cause defective B cell responses against SARS-CoV-2?

IL-4 is pleiotropic and could theoretically cause negative effects on immune responses. However, based on phase II and III studies with dupilumab (an IL-4R $\alpha$-specific monoclonal antibody that blocks IL-4 and IL13 signaling) in the context of atopic dermatitis, chronic rhinosinusitis with nasal polyps and asthma, no increased risk of infections to viral or bacterial pathogens have been documented. ${ }^{44}$ Furthermore, dupilumab had no impact on responses to non-live vaccines. ${ }^{45}$

\subsection{Type 2 responses and eosinophils}

Does type 2 airway inflammation protect against COVID-19?

Allergic airway disease patients appear to be underrepresented among COVID-19 patients. This could be partly attributed to the low ACE2 expression detected in allergic patients, with or without concomitant asthma. ${ }^{46}$ Furthermore, allergen challenge, which induces $\mathrm{T}$ helper (Th)-2 inflammation, has been shown to reduced ACE2 expression in a murine model of asthma, and ACE2 expression was inversely associated with type 2 biomarkers (IL-13, IgE, exhaled nitric oxide fraction). ${ }^{47}$ These results are in line with previous work showing that decreased ACE expression in the airway epithelium of asthmatic subjects was associated with eosinophilic inflammation. ${ }^{48}$ Altogether, these data suggest that type 2 airway inflammation may reduce the susceptibility of SARS-CoV-2 infection by reduction of ACE2 expression.

Some COVID-19 patients present with eosinophilic inflammation. Is it a Th2-driven response against the 
virus or an innate immune response?

Eosinopenia has been reported in 50-70\% of severe COVID-19 patients. A minority of COVID-19 patients present with eosinophilic inflammation. ${ }^{22,49}$ The Th1/Th2 cytokine balance may play a role, particularly as it pertains to IL-5, which promotes eosinophilopoiesis and eosinophil survival and activation. Eosinophilic inflammation suggests the dominance of type 2 inflammation, which may play a protective role against SARS-CoV-2. On the other hand, it may be the result of a hypersensitivity reaction to drugs used to treat COVID-19. ${ }^{50-52}$

Do eosinophils exert antiviral activity in COVID-19 patients?

Anti-IL-5 treatment, which induces eosinophil deficiency, results in a higher viral load in influenza and rhinovirus infection. This might be due to the ability of eosinophils to bind and inactivate the influenza A virus and respiratory syncytial virus (RSV). ${ }^{53}$ A similar role seems possible in SARS-CoV-2 infection, where type-2 asthma patients potentially benefit from antiviral eosinophil responses. On the other hand, COVID-19 post-mortems did not show lung eosinophilia ${ }^{51}$, which argues against its local protective role in SARS-CoV-2 infection, although it is important to control for glucocorticoid-driven eosinophil reduction in these studies. ${ }^{50}$

What is the mechanism underlying eosinopenia in COVID-19 patients?

Eosinopenia is commonly reported in severe COVID-19. ${ }^{54,55}$ The underlying mechanisms are largely unknown and most likely multifactorial. A number of possible explanations have been proposed: decreased eosinophilopoiesis; defective eosinophil egression from the bone marrow; and eosinophil apoptosis induced by type 1 IFN released during the acute infection. ${ }^{50}$ Also, increased eosinophil migration and retention within inflamed tissues has been described, ${ }^{56}$ but disputed for the aforementioned reasons. ${ }^{51}$

Do eosinophil-targeting biologics affect COVID-19 patients?

There is no evidence for an enhanced susceptibility of patients on anti-IL-5/IL-5R treatment to develop viral infections. Observational studies in COVID-19 patients reported elevated eosinophil counts with a favorable outcome, whereas eosinopenia was observed in more severe cases. ${ }^{22,57}$ Neither was there proof of causation nor evidence for enhanced tissue presence in lungs of COVID-19 patients. ${ }^{58}$

Do IL-5-targeting therapies for asthma have a protective effect in COVID-19 patients with severe asthma who are already receiving these therapies?

There is neither evidence for a protective effect of these biologicals nor a negative effect regarding SARS$\mathrm{CoV}-2$ infection. Importantly, maintaining proper asthma control is imperative and so is to follow up on severe asthmatics during the COVID-19 pandemic, for example via telemedicine. ${ }^{44}$

\section{$2.3 \mathrm{~T}$ cells and lymphopenia}

Is $\mathrm{T}$ cell function impaired in SARS-CoV-2 infection?

SARS-CoV-2 infects human T cells via CD147-binding. ${ }^{59} \mathrm{~T}$ cells are severely affected by SARS-CoV-2, which reduces $\mathrm{T}$ cell counts nearly 2 times below the reference limit. This effect is more pronounced in critically ill COVID-19 patients. ${ }^{49,60,61}$

What is the specificity of the T-cell response generated in COVID-19 patients?

Circulating SARS-CoV-2-specific CD8+ and CD4+ T cells have been reported in $70 \%$ and $100 \%$ of COVID19 convalescent patients, respectively. ${ }^{62} \mathrm{CD} 4+\mathrm{T}$ cell responses to spike were robust and correlated with SARS-CoV-2-specific-IgG and -IgA titers. The M, spike and N proteins each accounted for 11-27\% of the total CD4+ response, with additional responses commonly targeting nsp3, nsp4, ORF3a and ORF8, among others. For CD8+ T cells, spike and M proteins were recognized, with at least 8 SARS-CoV-2 ORFs targeted. Interestingly, SARS-CoV-2-reactive CD4+ T cells were detected in 40-60\% of unexposed individuals, which 
indicate cross-reactive $\mathrm{T}$ cell recognition between circulating 'common cold' coronaviruses and SARS-CoV$2 .^{62}$

Is a long-term T-cell memory established during SARS-CoV-2 infection?

Three SARS-recovered individuals, 9- and 11-years post-infection, were analyzed for T-cell responses against 550 SARS-CoV peptides that may share homology with MERS-CoV. SARS-specific memory T cells persisted at 9 and 11 years post-SARS infection in the absence of antigen exposure. ${ }^{63}$ Based on these data, it is likely that specific SARS-CoV-2 epitopes elicit a persistent $\mathrm{T}$ cell response, which may also confer protection against other 'common cold' coronaviruses. ${ }^{62}$ However, long-term studies on the natural history of SARS$\mathrm{CoV}-2$ infection are pending.

What are the hypothetical mechanisms of lymphopenia?

Different mechanisms have been proposed for lymphopenia: 1) T cell exhaustion. The expression of programmed cell death-1 marker (also known as PD-1), which is associated with T-cell exhaustion, was higher in T cells from COVID-19 patients than in healthy controls; the expression of PD-1 and Tim-3 (another exhaustion marker) increased as COVID-19 progressed. ${ }^{64}$ 2) Activation of the P53 signaling in lymphocytes, which suggests a role for apoptosis for in lymphopenia. 3) Lymphocyte pyroptosis, which induces lymphopenia and may be proinflammatory. ${ }^{65}$ 4) T-cell infection with SARS-CoV-2, which may also cause a cytopathic effect on infected $\mathrm{T}$ cells. 5) Other mechanisms of lymphopenia that remain to be studied are bone marrow suppression during cytokine storm syndrome (CSS; see below) and sequestration in the lungs during extensive bilateral pneumonia. ${ }^{49}$

Can lymphopenia be an early predictor of COVID-19 severity?

Lymphopenia can be used as an early predictor of severity and clinical outcome. A significant reduction in lymphocyte counts was common in severe and critically ill COVID-19 patients. A continuing or gradual decrease of lymphocyte counts was indicative of poor prognosis and usually required ICU admission (Table $1)^{49}$. In agreement with this, a number of studies have identified lymphopenia as an independent risk factor for mortality in COVID-19. ${ }^{22,66}$

Which cells are particularly decreased in lymphopenia?

In COVID-19 patients, decreases were observed in total lymphocytes, CD4+ and CD8+ T cells, B cells and natural killer cells. T cell and natural killer cell counts were below normal levels, while B cell counts were at the low end of the normal range. A reduction in specific subsets of lymphocytes, such as CD16+CD56+ natural killer cells and regulatory $\mathrm{T}$ cells, was reported in severe COVID-19 patients. ${ }^{49}$

\subsection{Immunopathology, immunosuppression and immune regulation}

What is meant by CSS?

CSS is associated with a wide variety of diseases, both infectious and noninfectious. It is a complex cascade of multicellular activation events that leads to an excessive or uncontrolled release of proinflammatory cytokines. CSS-associated inflammation begins at a local site and spreads throughout the body via the systemic circulation and can cause multi-organ failure and hyper-ferritinemia. ${ }^{49,67}$

Which cells are critically contributing to CSS in severe COVID-19?

CSS encompasses the activation of large numbers of blood cells, including B cells, natural killer cells, macrophages, dendritic cells, neutrophils, monocytes, resident tissue cells and epithelial and endothelial cells. Their activation cause a massive release of pro-inflammatory cytokines, which drives pathology ${ }^{68}$ The cells involved in CSS during COVID-19 have not been fully determined yet. In SARS-CoV and MERS-CoV infection, airway epithelial cells, dendritic cells and macrophages were the most important cell types releasing a large amount of proinflammatory cytokines. ${ }^{49,69}$

Which cytokines are most elevated during CSS? 
Multiple proinflammatory cytokines and inflammasome activation may contribute to CSS pathogenesis. ${ }^{49}$ Elevated serum ferritin, IL-6, IL-1 $\beta$, IFN- $\gamma$, CXCL10 (known as IP-10) and CCL2 (known as MCP-1) levels have been observed in the pathogenesis of severe COVID-19. ${ }^{50,70} \mathrm{~A}$ recent study compared 48 cytokines in 53 COVID-19 patients and 8 healthy individuals and found that 14 of them were increased in COVID-19: IFN$\gamma$, IL-1R $\alpha$, IL-2R $\alpha$, IL-6, IL-10, IL-18, hepatocyte growth factor, monocyte chemotactic protein-3, monokine induced $\gamma$-IFN, macrophage colony-stimulating factor, granulocyte colony-stimulating factor, macrophage inflammatory protein $1 \alpha$, cutaneous T-cell-attracting chemokine and IP-10. A consistently high level of IP-10, monocyte chemotactic protein-3 and IL-1R $\alpha$ was associated with deterioration and fatal outcome. ${ }^{71}$

Which other diseases can also develop CSS?

CCS can also develop in other infectious diseases such as bacterial sepsis, leptospirosis, Ebola and other hemorrhagic fevers, influenza, other pathogenic coronavirus infections including SARS-CoV and MERSCoV, severe RSV infection, and non-infectious diseases such as blunt trauma, and as a side effect of immunestimulatory drugs. ${ }^{49,67}$

Does systemic immunosuppression influence the course of COVID-19?

Immunosuppression is a double-edged sword in viral infections. ${ }^{72}$ Patients receiving systemic immune suppression (e.g. , chemotherapy) at the time of infection tend to develop a severe form of the disease. There are conflicting results regarding systemic corticosteroid treatment but their usage is not generally recommended in viral infections. ${ }^{49,73,74}$ However, CSS treatment requires systemic immune suppression. Therefore, immune suppression may facilitate viral infection but, at advanced stages of infection, it may be beneficial to counteract immunopathology due to excessive inflammation or CSS.

\section{Are primary immunodeficiency patients at increased risk to develop severe COVID-19?}

Primary immunodeficient patients are a high-risk group in the current pandemic, but to date it is unknown if a particular immunodeficiency poses a higher risk of severe disease. International primary immunodeficiency monitoring is being carried out and few cases have been documented. Patients at higher risk are those with complications resulting from their primary immunodeficiency and strict follow-up must be done in those cases. A consensus has been established that baseline chronic treatment should be continued in those patients if they are asymptomatic or mildly symptomatic. Furthermore, recommendations regarding primary immunodeficient patients adhere to individual national guidelines emphasizing social distancing and strict hygiene measures. Systematic testing of primary immunodeficient patients is not advised, however recommendations may change as the pandemic evolves. ${ }^{75}$

What is the role of $\mathrm{T}$ regulatory cells in COVID-19 pathogenesis?

There are no longitudinal studies analyzing T regulatory cells in COVID-19. A limited number of studies have reported decreased numbers of circulating T regulatory cells (CD3+CD4+CD25+CD127low+) as a part of lymphopenia. Further studies are needed to explore their roles in COVID-19 pathogenesis as well as in controlling severe tissue injury or CSS. ${ }^{49,76}$

Does metabolic fitness at the cellular and individual level affect COVID-19?

Systemic dysregulation of metabolism, such as that seen in obesity and diabetes is a risk factor of SARSCoV-1 and SARS-CoV-2 infection and of COVID-19 severity ${ }^{58}$. These diseases lead to chronic systemic inflammation, upregulation of SARS-CoV-2 receptors in the lungs and the periphery, and they disturb the glucose and lipid metabolism of tissues and immune cells. ${ }^{14,77,78}$

What is the pathogenesis of acute respiratory distress syndrome (ARDS) in COVID-19?

ARDS is an acute life-threatening inflammation of the lung due to infection, trauma, or inflammatory conditions. Excessive inflammation leads to alveolar damage and increased permeability of endothelial and epithelial cells. This results in protein-rich fluid accumulation in the interstitium and the air space, which causes impaired gas exchange and hypoxemia. Reactive oxygen species, leukocyte proteases, chemokines, and 
cytokines also contribute to lung injury. The barrier impairment of the lung microvascular barrier is central to the pathogenesis of ARDS. ${ }^{79}$ Pulmonary vascular endothelial injury in association with the presence of the intracellular virus and disrupted cell membranes contribute to the increase of endothelial permeability. COVID-19 patients with ARDS had a histological pattern of diffuse alveolar damage with perivascular $\mathrm{T}$ cell infiltration. In addition, alveolar capillary microthrombi, secondary to endothelial injury, in patients who died of COVID-19 may be an important cause of refractory hypoxia in ARDS. ${ }^{49,74,80,81}$

What are the clinical phenotypes of ARDS in COVID-19 patients?

In COVID-19 patients, ARDS is more common in the elderly, those with multiple comorbidities, and those with continuing or gradually progressing neutrophilia and lymphopenia, and a higher level of C-reactive protein, lactate dehydrogenase, D-dimer and procalcitonin. ${ }^{49,74}$ There are at least 2 clinical phenotypes of ARDS: 1) near normal pulmonary compliance with isolated viral pneumonia; 2) decreased pulmonary compliance. ${ }^{81,82}$

What specific therapies can be suggested for ARDS?

Different treatments were suggested for ARDS. Corticosteroid treatment is generally not recommended, although widely used in critically ill patients. Convalescent plasma (CP) was administered to a small number of patients and was associated with virus clearance and clinical improvement (Table 2 ). Low tidal mechanical ventilation, positive end-expiratory pressure, prone positioning ventilation, and fluid management guidelines were associated with improved outcomes. Extracorporeal membrane oxygenation could be used according to the inclusion and exclusion criteria of the EOLIA trial. Other potential therapies such as mesenchymal stem cell therapy and cytokine inhibitors are still in trials and without definite results. ${ }^{49,83}$

\section{Is Bacille Calmette-Guerin (BCG) vaccination protective against SARS-CoV-2?}

BCG vaccination induces metabolic and epigenetic modifications by enhancing trained immunity (innate immunity to subsequent infections). It was hypothesized that general BCG vaccination policies adopted by different countries might have impacted the transmission patterns and/or COVID-19-associated morbidity and mortality. ${ }^{84,85}$ BCG vaccination in childhood was not protective against SARS-CoV-2 infection in an Israeli cohort. ${ }^{86}$ In contrast, randomized controlled trials of BCG-Danish indicated immunomodulation against pre-COVID-19 respiratory infections with fewer deaths from sepsis and pneumonia. Two clinical Danish trials of BCG-Danish (BRACE and BCG-CORONA) are evaluating its impact on healthcare workers as pertains to COVID-19 infection and severity. ${ }^{87,88}$

\section{What is the mechanism underlying Kawasaki syndrome in the context of COVID-19?}

The mechanisms underlying Kawasaki disease -a generalized vasculitis, in young children, of unknown, potentially post-viral etiology- are poorly understood. The rare COVID-19-associated inflammatory syndrome also features vasculitic changes, affects older children too and is often only associated with positive SARS-CoV-2 serology, but not viral shedding. Its mechanisms need to be elucidated and may include post-infectious, antibody and immune-complex mediated pathology. In adults, there are occasional cases of COVID-19-associated cutaneous vasculitis, possibly a localized manifestation of the disease that leads to severe generalized vasculitis in some children. ${ }^{89-91}$ Interestingly Kawasaki-like disease was not reported in Chinese cases and the first months of European cases. The season of the disease and environmental factors should be considered. The Chinese epidemic was mainly from January to March whereas the USA epidemic started in mid-March and is still ongoing.

Which acute phase reactants are the most decisive ones for the follow-up of COVID-19 patients?

Initial results of acute phase reactants such as C-reactive protein, alanine transaminase, lactate dehydrogenase, D-dimer, procalcitonin, serum ferritin and IL-6 on admission were used to evaluate the severity and predict the mortality. However, dynamic changes of these variables will be more precise in predicting the recovery or progression of COVID-19. Continuing or progressively increasing levels of C-reactive protein, 
procalcitonin, D-dimer and lactate dehydrogenase were shown to be associated with a high risk of death in severe COVID-19 patients. ${ }^{22,49,92}$

\section{Section 3: Diagnosis of COVID-19}

What are the principal signs of a SARS-CoV-2 infection?

Patients with acute respiratory illness (i.e ., fever and at least one sign/symptom of respiratory disease such as cough or shortness of breath) and a history of contact with a confirmed or probable COVID-19 case during the 14 days before symptom onset. Patients with any acute respiratory illness in the context of a pandemic should have SARS-CoV-2 infection in their differential diagnosis. Special attention should be given to patients with sudden onset of anosmia, loss of taste, gastrointestinal symptoms or skin lesions without respiratory symptoms who also have epidemiological links. ${ }^{5,22,93}$

What is the importance of smell loss in the diagnosis of COVID-19?

Smell loss is now a well-established diagnostic symptom of COVID-19 and can be present in otherwise asymptomatic patients, making it a useful tool in initial diagnosis. ${ }^{94}$ This has resulted in anosmia to be included in the list of symptoms used in early screening tools for possible COVID-19 in many international bodies. $^{94}$

What are the prognostic parameters of severe COVID-19?

Rapidly progressive respiratory failure and sepsis, elevated serum proinflammatory cytokine levels, elevated acute phase reactants (e.g. C-reactive protein), cell-free-hemoglobin-leukopenia and markers of disseminated intravascular coagulation. ${ }^{95}$

What is the most reliable method to determine positive COVID-19 cases?

RT-PCR to generate cDNA from SARS-CoV-2 RNA extracted from respiratory samples, followed by quantitative PCR (Figure 2 ). ${ }^{96}$ Common gene targets for SARS-CoV-2 include the envelope, nucleocapsid, spike, RNA-dependent RNA polymerase, and ORF1 genes. It is recommended to include in the analysis, at least, 2 target genes. ${ }^{97}$

What is the most suitable location to perform a swab for SARS-CoV-2 detection via RT-PCR?

Nasopharyngeal and oropharyngeal (throat) swabs are the primary specimens for SARS-CoV-2 RT-PCR testing. Lower respiratory tract specimens (i.e. sputum, endotracheal aspirate or bronchoalveolar lavage) may have higher viral loads and be more likely to yield positive tests. However, these locations carry a high risk of aerosolization and therefore should be reserved for severe patients with a negative test on an upper respiratory tract specimen and high suspicion for lower respiratory tract SARS-CoV-2 infection. ${ }^{98,99}$

Is serology a feasible way to screen for SARS-CoV-2 infection at a population level?

Serology is useful to determine prior exposure to SARS-CoV-2 within a given period of time (the length of time following infection that one remains positive is unknown). Detection of antibodies specific to the receptor binding domain of the spike protein indicates neutralization capacity, hence informing better about the development of protective immunity. ${ }^{33,96}$

What is the relationship between clinical manifestations and SARS-CoV-2 seroconversion?

The antibody response occurs later than initiation of symptoms as well as of the detection of viral RNA by RT-PCR in respiratory tract specimens, which usually peaks within the first week of symptom onset (Figure 2 ). Although antibodies to SARS-CoV-2 have been detected as early as the first week after symptom onset, IgM, IgA and IgG seroconversion commonly occurs between the $2^{\text {nd }}$ and $3^{\text {rd }}$ week of clinical illness onset. Thereafter, IgM starts to decline, reaching low levels by week 5 and almost disappears by week 7 , while IgA and IgG persist beyond this period. ${ }^{33,96,100}$ 
What are the main approaches for the development of a rapid and specific point-of-care diagnostic test for COVID-19?

The main approaches include nucleic acid amplification on respiratory samples using mobile devices (RTPCR or isothermal nucleic acid amplification) and viral antigens or host antibodies (viral protein fragments) detection using immunoassays. ${ }^{101}$ However, individual tests need validation in large populations before use and their sensitivity, specificity, positive and negative predictive values have to be accurately ascertained. Otherwise, they may lead to COVID-19 under or over diagnosis, thus undermining the public health efforts to control the disease. ${ }^{102}$

There is a high rate of false negatives with rapid serology tests for SARS-CoV-2, is there an alternative method to determine positive cases?

A high rate of false negatives with antigen point-of-care assays may be due to the fact that the majority of patients produce antibodies against SARS-CoV-2 only after the second week after of infection. ${ }^{103}$ Furthermore, an effective antibody response is connected with several determinants, comprising severity of the disease, age and nutritional status of the patient, medications administered and concomitant infections. ${ }^{102} \mathrm{Nu}-$ cleic acid amplification using RT-PCR directly targeting the virus is not affected by the above-mentioned limitations. ${ }^{104}$ However, false-negative real-time RT-PCR tests for the diagnosis of SARS-CoV-2 were reported by Zhang et al . in a retrospective study of 290 hospitalized and confirmed COVID-19 patients in Wuhan, China. Forty-one of them initially tested negative for SARS-CoV-2 and 21/41 tested positive by the second real-time RT-PCR test and an additional 13/41 patients by the third test. Almost all patients (98\%) tested positive by the fifth and final test. ${ }^{105}$ Patients with an initial positive SARS-CoV-2 result had an increased risk of progressing to severe cases. Altogether, these findings underscore how the timing of the immune response influences RT-PCR tests for SARS-CoV-2, and the importance of combining RT-PCR data with seroconversion for COVID-19 diagnosis.

When can a suspected/confirmed case of COVID-19 discontinue home isolation/quarantine?

The decision to discontinue home isolation/quarantine should be adapted to specific groups of patients based on factors such as symptom severity, healthcare systems' capacity, laboratory diagnostic resources and local epidemic status. Patients with suspected or confirmed symptomatic COVID-19 can discontinue self-isolation/quarantine if all the following 4 conditions are met: a) resolution of fever (without the use of fever-reducing medications) for at least 3 days; b) clinical improvement in respiratory symptoms (e.g. , cough, shortness of breath) for at least 3 days; c) at least 8 days have passed since the onset of symptoms for mild cases or at least 14 days for severe cases and immunocompromised patients; d) 2 negative RTPCR tests from respiratory specimens taken 24 hours apart. If there is limited or no testing capacity, the combined symptom/test-based strategy should be reserved to hospitalized COVID-19 cases and healthcare workers, whereas for mild or asymptomatic COVID-19 cases (suspected or confirmed) the symptom-based strategy (condition a) AND b) AND c)) without lab testing is considered acceptable to end the self-isolation period. ${ }^{106}$

\section{Section 4: Organization of allergy outpatient clinics and laboratories during the COVID-19 pandemic}

What are the emergency measures in an ongoing allergy clinic during the COVID-19 pandemic?

Strategies for risk minimization should be elaborated, harmonized and followed as such in allergy clinics, centers and practices. ${ }^{107}$ In the EAACI/ARIA Position Paper by Pfaar et al. ${ }^{108}$ experts in the field have developed practical recommendations for optimizing allergic patients 'care whilst ensuring the safety of all health care professionals (Figure 3 ). General guidance from national health authorities should be strictly followed (i.e., World Health Organization, WHO; European Centre for Disease Prevention). In-person consultations should be minimized to the lowest necessary level and triaged by telemedicine whenever possible (Figure 4 ). ${ }^{109}$ Special attention should be paid to data-protection in adherence to national data-security and -protection laws. Non-delayable diagnostic and therapeutic measures should strictly follow reasonable 
preventive measures. Several specific considerations regarding diagnostic and therapeutic measures are important in different allergic diseases (Figure 5 ). Moreover, socio-psychological aspects play a fundamental role in the care of allergic patients during the current pandemic and should be especially recognized and followed. Stress caused by isolation and stigmatization due to allergic symptoms may amplify the development of allergic symptoms. ${ }^{110}$

Is pre-visit specific telephonic triage useful to identify patients possibly infected with SARS-CoV-2?

Virtual doctor consultations have been regarded as an alternative to on-site clinical encounters and are increasing during the COVID-19 pandemic. ${ }^{108}$ Initially, pre-visit telephonic communication is helpful to screen for patients with potential SARS-CoV-2 infection ${ }^{111}$ The epidemiological history should be investigated to determine if patients have fever or respiratory symptoms. In addition, pre-visit specific triage improves the efficiency of the patient's visit, thus reducing the length of stay in the hospital. To reduce face-to-face meetings, physicians can train some patients to self-treat at home based on the diagnosis obtained through a telephone consultation.

Should every allergic patient be tested for SARS-CoV-2 prior to coming to the clinic?

A strict screening protocol is needed to identify SARS-CoV-2 infected patients. Ideally, only SARS-CoV2 negative patients (diagnosed via RT-PCR and/or rapid test) should come to the clinic. In places where systematic testing is unavailable, at least, normal temperature and negative epidemiological history should be mandatory to proceed to the outpatient departments. Patients with a body temperature higher than $37.3^{\circ} \mathrm{C}$ should have additional screening examinations, including routine blood tests, chest computed tomography scanning and even throat swabs for SARS-CoV-2 RT-PCR testing. ${ }^{112}$

What should be considered when performing diagnostic procedures during the COVID-19 pandemic?

The indication and urgency of the tests for diagnosis should be considered. Contraindications for skin, provocation and lung function tests can be explained beforehand to the patient, which helps to avoid unnecessary in-person consultations. ${ }^{108}$ Any test generating aerosol particles should be avoided because it is considered high risk .

What kind of procedures should be performed in biosafety level (BSL)-2 and -3 laboratories during the COVID19 pandemic?

Personal protective equipment (PPE) must be used when collecting biological samples. Biological samples collected on-site from suspected or confirmed COVID-19 patients (e.g. antibody assays, RNA isolation, flow cytometry) should be processed following BSL-2 practices. During and after the COVID-19 pandemic, the usage of BSL-2 facilities is mandatory for all newly arriving patient samples to prevent spreading the disease. Research procedures involving SARS-CoV-2 isolation or culture should be conducted in a BSL-3 facility. ${ }^{108,113}$

\section{Section 5: COVID-19 and allergic disease}

Do patients with allergic diseases have a higher risk of developing severe COVID-19?

Patients with common allergic diseases do not develop distinct symptoms or severe outcomes. Allergic children show a mild course similar to non-allergic children ${ }^{5}$. In a recent study of 182 hospitalized children, 43 of them were reported with allergies. Allergic rhinitis was the most prevalent allergic disease (83.7\%), followed by drug allergy, atopic dermatitis, food allergy and asthma. In this study, allergic children showed a reduced increase in acute phase reactants, procalcitonin, D-dimer and aspartate aminotransferase levels compared to all patients. There were no deaths in allergic children in that study. ${ }^{114}$

5.1 Allergic rhinoconjunctivitis

What is the strategy to distinguish between hay fever/pollen allergy and COVID-19 infection? 
Clinical history is very helpful to identify seasonality- and exposure-related symptoms driving the diagnosis of pollen-induced allergic rhinitis. An atopy test (in vivo or in vitro)reinforces the diagnosis. However, COVID19 can be superimposed on allergic rhinitis symptoms. ${ }^{108}$ Symptoms such as fever, fatigue and sudden loss of smell, are suggestive of COVID-19 and should be closely monitored.

What is the recommended mask to prevent allergic rhinitis symptoms during the COVID-19 pandemic?

N95 facial masks have been proven useful in reducing allergen exposure by blocking pollen access to nose and mouth. On the other hand, surgical masks do not protect against inhalation of small airborne contaminants and are not designed to seal tightly against the user's face, hence the contaminated air can pass through the gaps. ${ }^{115}$

Does allergic rhinitis impact the susceptibility of SARS-CoV-2 infection?

There are no conclusive data on the impact of allergic rhinitis on COVID-19 susceptibility ${ }^{116}$. However, a recent study with 24 allergic rhinitis patients demonstrated a reduction of ACE2 expression in nasal brush samples following an allergen challenge. ${ }^{46}$ Also, this study reported lower ACE2-expression in the epithelium of asthmatic patients. Altogether, these data suggest that allergic rhinitis patients may have lower risk of SARS-CoV-2 infection as compared to non-allergic individuals, but further studies are needed.

Are allergic rhinitis patients at higher risk of severe COVID-19?

Although limited, the available evidence suggests that, compared to non-allergic individuals, allergic rhinitis patients are not at higher risk of developing severe COVID-19. In a Chinese cohort of 140 hospitalized COVID-19 adult patients, allergic rhinitis and asthma were not risk factors for SARS-CoV-2 infection. ${ }^{22} \mathrm{~A}$ similar finding was also reported in children. In a recent study addressing the clinical characteristics of 182 children with COVID-19, 43 of them had an allergic condition, which was mainly allergic rhinitis (83.7\%). In this study, allergic children exhibited a disease progression comparable to that of non-allergic children. ${ }^{114}$ Prospective trials are urgently needed.

What are the recommendations for patients suffering from severe conjunctivitis and keratoconjunctivitis during the COVID-19 pandemic?

Patients should continue baseline treatment as established by their physician and current guidelines. According to a panel of experts, low-dose corticosteroids or antiallergic eye drops continue to be the first line of treatment for allergic conjunctivitis during the current pandemic. Although there is no evidence on the possible effect of SARS-CoV-2 on patients using ocular immunomodulating drugs, in patients with vernal keratoconjunctivitis and allergic keratoconjunctivitis the use of local immunomodulatory treatment is considered safe in non-infected patients and should be monitored closely in those with active infection. The use of systemic immunosuppressants for severe COVID-19 cases should be considered on an individual basis ${ }^{117}$.

What are the recommendations for patients suffering from allergic rhinitis during the COVID-19 pandemic?

There is no scientific evidence that treatments for allergic rhinitis either increase susceptibility to SARSCoV-2 infection or the severity of COVID-19. Therefore, allergen avoidance measures, nasal saline douches, and background controller therapies recommended by current guidelines for allergic rhinitis, such as nasal corticosteroids or second-generation H1-blockers, should be continued as prescribed, both in non-infected and COVID-19 diagnosed patients. ${ }^{108,116}$ Such treatments can help reduce the spreading of an eventual SARS-CoV-2 infection by targeting characteristic clinical features of allergic rhinitis, such as sneezing and rhinorrhea, and might prevent unnecessary visits to physicians and emergency departments. Specific recommendations apply to patients with allergic rhinitis treated with AIT or biologics. These therapies should be suspended in COVID-19 diagnosed patients or suspected cases for SARS-CoV-2 infection until resolution of the disease is established (e.g. via a negative SARS-CoV-2 test in connection with clinical recovery). ${ }^{108,118}$

\subsection{Chronic rhinosinusitis and other upper respiratory tract diseases}

Is there a difference in the mechanism driving anosmia in chronic rhinosinusitis and SARS-CoV-2 infection? 
The loss of smell in chronic rhinosinusitis is caused by type- 2 inflammation of the olfactory epithelium. ${ }^{119}$ In COVID-19, the exact mechanism of potential olfactory neuropathy is still unclear. ${ }^{120}$ However, a study found that sustentacular cells of the olfactory epithelium express ACE2 and TMPRSS2, which enable SARS-CoV-2 entry and may subsequently impair the sense of smell. ${ }^{121}$

Is intranasal corticosteroid treatment recommended for patients with COVID-19 that present with loss of smell?

A considerable percentage of COVID-19 patients experience loss of smell as an early sign of the disease. ${ }^{94}$ In many patients smell recovers in 1-2 weeks and there is no indication that intranasal corticosteroid treatment has a positive impact on the recovery. ${ }^{122}$ On the other hand, there is no evidence suggesting that this treatment has a negative impact on symptomatology and/or development of COVID-19. Consequently, it is recommended to continue regular intranasal corticosteroid treatment for chronic rhinosinusitis. ${ }^{108,116}$

What are the recommendations for performing nasal endoscopy surgery in COVID-19 patients?

Diagnostic procedures involving upper airway manipulation, such as nasal endoscopy, should be considered high risk for viral transmission. Before clinical examination, it is recommended to question all patients about contact with confirmed COVID-19 patients, fever, respiratory symptoms and recent sudden loss of smell and/or taste. During nasal endoscopy, distance between the endoscopist and patient can be maximized by using a tower with a camera, screen and light source, rather than using an eyepiece. Also, manipulations should be limited if possible, (i.e. nasal inspection vs debridement with suction and/or forceps). The use of local anesthetic sprays can be replaced by alternatives such as soaked pledgets because atomized anesthesia can aerosolize the virus. ${ }^{123}$ Given that the COVID-19 status of patients consulting the outpatient rhinology clinic is often unknown and the risk of transmission through clinical procedures is high, wearing adequate PPE is mandatory. ${ }^{108,124}$ For all surgical cases, pre-operative screening of the COVID-19 status of the patient is recommended to adapt the PPE accordingly. In case of an emergency where COVID-19 screening would imply an unacceptable time-delay, the patient should be considered as COVID-19 positive and PPE used. ${ }^{123}$

Is corticosteroid treatment before surgery for chronic rhinosinusitis with nasal polyps recommended during the pandemic? And if so, intranasal or oral?

The use of intranasal corticosteroids does not seem to have a negative impact on symptoms and/or development of COVID-19. ${ }^{116}$ Therefore, intranasal corticosteroid treatment should be continued perioperatively if possible. The use of corticosteroids either during an exacerbation or perioperatively should be carefully considered on a 'per-patient' basis. Recent guidance from the WHO has advised against the use of systemic corticosteroids if COVID-19 is suspected due to concerns that these agents may impair innate antiviral immune responses. ${ }^{125}$

What are the treatment recommendations for COVID-19 children with chronic otitis media with effusion?

Chronic otitis media with effusion is a common childhood disease usually with the absence of signs or symptoms of acute ear infection. It is therefore preferable to treat COVID-19 first and delay elective surgery. The indication and choice of surgery (e.g. , tympanostomy tubes and/or adenoidectomy) should comply with the professional Clinical Practice Guidelines. ${ }^{126,127}$

\subsection{Asthma}

How can an asthma exacerbation be differentiated from a SARS-CoV-2 infection?

An asthma exacerbation is difficult to differentiate from COVID-19 ARDS or pneumonia by the patient, especially if it is triggered by rhinovirus, or other common respiratory viruses, because both conditions have dry cough and dyspnea. The British Thoracic Society advises patients with asthma experiencing fever, fatigue and loss of taste or smell to alert their physician as these are indicative of COVID-19. ${ }^{128}$ The distinction can be made by the physician based on the presence of wheeze, which is generally (but not always) absent in COVID-19 pneumonia, as well as high-resolution chest tomography and viral diagnostic tests. ${ }^{108}$ 
Are COVID-19 patients with asthma at a higher risk of severe COVID-19 than the general population?

Patients with controlled asthma are not at higher risk of severe infection than the general population. ${ }^{129,130}$ In fact, ACE2 expression was shown to be decreased in patients with allergic asthma ${ }^{46}$ and in those receiving inhaled corticosteroids. ${ }^{131}$ However, ACE2 expression in asthmatic patients was increased in AfricanAmericans, in males and associated with diabetes. ${ }^{46}$ On the other hand, uncontrolled asthma is a risk factor, thus all efforts should be focused on treating asthma by regular use of controller medication, including inhaled corticosteroids and biologicals. ${ }^{132}$

Are patients on inhaled corticosteroids maintenance treatment at higher risk of infection or more severe COVID-19?

There is no evidence available that patients on inhaled corticosteroids are at higher risk of COVID-19 infection or of more severe symptoms than the general population. It is strongly advised by international scientific societies that patients continue with their routine control medication including inhaled corticosteroids during the pandemic. ${ }^{116,133}$

Corticosteroids inhibit rhinovirus and RSV-induced cytokine release in vitro. Do inhaled corticosteroids have a protective effect against SARS-CoV-2?

Recent evidence indicates that inhaled corticosteroid treatment reduces the expression of viral membrane receptors used to infect the human airways in a dose-dependent manner. ${ }^{131}$ On the other hand, the immune suppression exerted by corticosteroids may impair anti-viral responses. ${ }^{125}$ However, there are no clinical studies investigating the effect of inhaled corticosteroid on SARS-CoV-2 infection rates.

Given the current restrictions, should spirometry and other lung function tests for initial asthma diagnosis be performed?

Spirometry is essential for the diagnosis of new asthma cases as stated by the Global Initiative for Asthma guidelines. Therefore, it should be conducted, but under special conditions (negative pressure chamber,etc .) and only in areas with low SARS-CoV-2 infection incidence. Healthcare providers performing lung function testing need to wear maximum PPE (filtering face-piece particles 2 or 3 face mask, goggles, or disposable face shield covering the front and sides of the face, clean gloves, and clean isolation gowns), and the spirometer devices should be properly disinfected between patients. ${ }^{134}$ An alternative, less precise, is monitoring morning and evening peak expiratory flow variability over a week. ${ }^{135,136}$

Should routine spirometry and lung function control be performed in asthmatic patients during the COVID19 pandemic?

The Global Initiative for Asthma guidelines state that routine spirometry should be avoided, especially in high-risk areas of COVID-19 transmission. If spirometry needs to be performed, maximum PPE should be used. ${ }^{133}$ The treatment of asthmatic patients can be monitored using personal devices measuring forced expiratory volume and peak expiratory flow. Many of these devices are equipped with remote transmission functions and thus are amenable for the telemedicine management of patients. ${ }^{137}$

Should asthma exacerbations be treated with oral corticosteroids during the COVID-19 pandemic?

There is no evidence suggesting that the current approach to treat asthmatic patients during an exacerbation should change during the COVID-19 pandemic. Moreover, there is no proof that a short course of systemic corticosteroids impacts the evolution of COVID-19. Thus, oral corticosteroids should be given as usual for the treatment of an asthma exacerbation. ${ }^{128,133}$ In the few cases in which patients are treated with long-term oral corticosteroids in addition to their high dose inhaled corticosteroids this should be continued in the lowest dose possible to prevent exacerbations. ${ }^{133}$ The cause of the asthma exacerbation should be studied thoroughly to rule out potential exacerbations due to viral infections. ${ }^{75}$

What is the safest way to administer a medication that creates airborne particles during the COVID-19 pandemic? 
The preferred treatment is a pressurized metered-dose inhaler with a spacer. Each patient should have an individual spacer, and this should not be shared at home. The use of nebulizers should be avoided when possible because they increase the risk of disseminating viral particles, which could affect other patients and healthcare personnel. ${ }^{133}$

What is the correct way to manage anti-IgE treatment during the COVID-19 pandemic?

Anti-IgE treatment with omalizumab (or other biologics indicated for asthma) should be continued in noninfected patients. Self-administration devices at home, whenever this option is available, are preferred, to minimize face-to-face contact in the clinic. In infected patients, omalizumab administration should be delayed until complete clinical recovery and viral clearance is achieved. ${ }^{44,138}$

CSS in COVID-19 patients is characterized by increased IL-6 levels. Given that an IL-6/Th17 endotype is associated with severe asthma in obese patients, are obese asthmatic patients more likely to develop severe COVID-19?

Obesity, as part of the metabolic syndrome, increases the risk of severe COVID-19. This is due to the preexistent systemic low-grade inflammation and increased expression of SARS-CoV-2 entry receptors (ACE2, TMPRSS2 and CD147). ${ }^{139,140}$ Obese patients tend to have worse asthma control, increased hospitalizations and suboptimal response to standard controller therapy. Thus, both difficult-to-control asthma and underlying metabolic syndrome are risk factors for severe COVID-19. The IL-6/TH17 endotype encountered in late-onset obese asthma might be an additional risk factor. ${ }^{141,142}$

\subsection{Atopic dermatitis and other skin lesions}

What are the dermatological manifestations of COVID-19?

The dermatological manifestations of COVID-19 range from an un-specific macular erythematous rash, urticarial lesions, chickenpox-like vesicles and acro-ischemic lesions. ${ }^{143,144}$ They can result from local inflammation due to circulating immune complexes or from systemic manifestations leading to vasculitis and thrombosis. ${ }^{145}$ These patients are also at increased risk of drug hypersensitivity lesions (Figure 6 ). ${ }^{146}$

Are patients with epithelial barrier disorders at higher risk of skin complications?

There is no evidence that patients with barrier defects such as atopic eczema have a higher risk for SARSCoV-2 infection or skin complications during COVID-19. However, patients with atopic dermatitis are often on systemic immunosuppressants and should be monitored closely. Optimal topical treatment regime should also be encouraged in all patients. ${ }^{147}$

Does frequent hand washing for COVID-19 prevention increase the risk of atopic dermatitis?

Hand hygiene procedures are pivotal to prevent self-infection and virus spreading. However, extensive water contact enhances dry skin, disturbs the commensal microbiota and leads to barrier disruption in healthy individuals. Moreover, it exacerbates diseases with an intrinsic barrier defect such as atopic dermatitis. ${ }^{148,149}$ Effective skin-care after hand hygiene is therefore essential to prevent barrier disruption and sensitization events. Here, emollients containing hyaluronic acid, Vitamin E, ceramide or urea are recommended. ${ }^{150}$

Does dupilumab treatment increase SARS-CoV-2 infection susceptibility?

Dupilumab is approved for the treatment of moderate-to-severe atopic dermatitis. First data from Italy on dupilumab-treated non-infected in high epidemic areas, and current evidence from dupilumab trials, suggest no negative effect of dupilumab regarding viral infections ${ }^{151}$ with reports on a reduced number of herpes simplex superinfections and less bacterial superinfections. ${ }^{152-154}$

Should dupilumab treatment for atopic dermatitis patients be suspended or modified during the COVID-19 pandemic?

The current EAACI statement on the usage of biologicals in the context of COVID-19 advices no change of therapy in non-infected individuals and to withhold/delay the application of biologicals for a minimum 
of two weeks or the resolution of the disease in case of SARS-CoV-2 infection. ${ }^{44}$ This is based on expert opinion in the light of missing data and may be adapted if more information becomes available.

Should patients presenting with acro-vasculitis be studied for coagulation defects and considered for preventive therapy even if they are asymptomatic?

Acro-ischemic lesions on toes and fingers have been identified in a subgroup of COVID-19 patients. ${ }^{22,155}$ The data available are scarce and it is unclear if preventive or active anticoagulation should be initiated. However, acro-ischemic lesions could predate other SARS-CoV-2 symptoms in children and young adults.

\subsection{Drug hypersensitivity}

How to differentiate skin lesions caused by COVID-19 itself from those secondary to drug hypersensitivity during the treatment of the disease?

COVID-19-induced skin lesions can be related to thrombovascular events (i.e. petechiae, acro-ischemia, dry gangrene) or to typical viral infections (i.e. erythematous rash, urticaria, maculopapular exanthema). ${ }^{146}$ Drug hypersensitivity has to be considered as a differential diagnosis, mainly in the second group, being a distinction difficult during the acute phase. Diagnosis relies mostly on clinical observations. In that regard, an accurate chronology of the reaction and the drug exposure timeline is very informative ${ }^{52}$. Laboratory and histopathological findings may also help.

Of the drugs being assessed for COVID-19 treatment, which ones are more immunogenic or associated with hypersensitivity reactions?

Immunomodulatory drugs (including azithromycin), hydroxychloroquine/chloroquine and IFNs, are the ones most frequently involved in hypersensitivity reactions. Most reactions are non-immediate and further studies are required to clarify whether this increased frequency is caused by the drug immunogenicity or simply derives from a greater consumption as compared to other treatments. ${ }^{146}$

Should drug provocation testing be performed during the COVID-19 the pandemic?

Drug provocation tests are not recommended because reactions can occur during the tests, including the generation and spreading of virus-containing aerosols. However, they may be considered after careful riskbenefit assessment in cases of urgent need, such as chemotherapy in cancer patients, perioperative drugs and radiocontrast media in subjects needing urgent procedures, and antibiotics if no effective alternative drug is available. ${ }^{108}$

Handling of allergen immunotherapy (AIT) during the COVID-19 pandemic

Should AIT in allergic rhinitis and/or asthma patients be interrupted to reduce visits to health care centers during the COVID-19 pandemic?

Most AIT products authorized for use in Europe indicate that AIT should be discontinued in case of infection; the same principle will apply to the COVID-19 pandemic. Patients on subcutaneous or sublingual AIT, who are diagnosed with COVID-19, those suspected of SARS-CoV-2 infection or symptomatic patients with a positive contact to SARS-CoV-2 individuals, AIT should be interrupted until the patient has recovered. In patients not infected or who have recovered from the infection, AIT could be continued (Table 3 ). These recommendations are conditional and could change as clinical data evolve. ${ }^{108,118}$

Should venom AIT be stopped during the COVID-19 pandemic?

AIT should continue in non-infected patients or those recovered from COVID-19. This is especially important in patients with life-threatening conditions such as venom allergy. It is possible to extend the intervals between vaccines during subcutaneous AIT, as done for inhalant allergens, to minimize visits to the allergy clinic. If venom AIT was stopped due to SARS-CoV-2 infection, it is unclear when it should be re-initiated because data from convalescent patients is scarce. ${ }^{118}$

What is the correct way to manage oral immunotherapy for food allergy during the COVID-19 pandemic? 
In patients diagnosed with COVID-19 or cases with suspected SARS-CoV-2 infection, oral immunotherapy dosing should continue as indicated in the dosing plan and in coordination with the treating physician. Oral immunotherapy can be continued in non-infected patients and those who have recovered from COVID19. In areas with high level of SARS-CoV-2 community transmission, visits to the allergy clinic for oral immunotherapy up-dosing should be postponed. ${ }^{108,118}$

\section{Section 6: Treatment of COVID-19}

Is it more important to treat the viral infection or the CSS in COVID-19 patients?

COVID-19 treatment entails 3 main approaches: 1) anti-viral; 2) systemic anti-inflammatory and immunologic; 3) symptomatic and supportive treatment. The patient's viral load detected at the onset of COVID-19 is associated with mortality. Consequently, SARS-CoV-2-specific anti-viral treatments, once licensed, are expected to be central to COVID-19 treatment. Systemic anti-inflammatory treatments are essential in severe COVID-19 cases with CSS as the latter is a decisive risk factor for mortality, multiorgan failure, ARDS and disseminated intravascular coagulation. For these reasons, COVID-19 treatments must induce quick viral clearance while precluding systemic inflammatory syndromes. ${ }^{49}$

In home-treated mild COVID-19 patients, what are the alarm symptoms to seek hospital assistance?

These patients are generally on symptomatic treatment. They need to look out for symptoms suggesting hypoxia or pneumonia, such as shortness of breath, deep shallow breathing, chest pains or persistent tachycardia. Special attention needs to be given to those with risk factors for disease progression, such as patients older than 65 years, cardiac or pulmonary comorbidities and immunosuppression. ${ }^{156,157}$

Which of the COVID-19 patients would benefit from anticoagulant treatment?

Prophylactic low molecular weight heparin, or heparin, has been recommended by the WHO in severe to critically ill COVID-19 patients. ${ }^{125}$ However, the International Society on Thrombosis and Haemostasis recommended that all hospitalized COVID-19 patients, not just those in ICU, should receive prophylactic low molecular weight heparin in the absence of contraindications. ${ }^{158}$

Does systemic corticosteroid treatment at the initial phases of COVID-19 prevent the immunopathology seen in severe cases?

During the SARS outbreak in 2003, corticosteroids did not change the course of the viral infection and delayed viral clearance. ${ }^{159}$ On the other hand, a retrospective study on SARS patients in Hong Kong suggested a better survival rate in patients treated with prednisolone for milder pneumonia or methylprednisolone in more severe cases. ${ }^{160}$ Recently, Chinese experts stated that, in COVID-19 patients, systemic corticosteroids should be considered on individual indications in a low-to-moderate dose and for no longer than a week. ${ }^{161}$ The National Institutes of Health in their COVID-19 Treatment Guidelines advises against the use of systemic corticosteroids in non-critically ill patients. ${ }^{162}$

Is there enough evidence to support that current COVID-19 treatments are better than placebo in terms of symptoms' severity and aftermath?

There are over 170 clinical trials on COVID-19 treatment registered now in the international databases and very few have been completed. Currently promoted pharmacological treatments are, at the most, based on anecdotic data collected in small numbers of COVID-19 patients. These studies did not satisfy evidence-based medicine criteria, but caught general attention through news media, for example hydroxychloroquine. ${ }^{163}$

Tocilizumab has been used for ICU patients with severe COVID-19, what is the rationale?

Tocilizumab is a humanized monoclonal antibody specific for IL-6R, and it is approved for the treatment of rheumatoid arthritis. A positive response to tocilizumab points towards an imbalanced innate immune response in severe COVID-19. Luo et al.${ }^{164}$ reported that of the 15 patients treated with tocilizumab, 7 of them critically ill, 11 of the patients recovered within a week. Prompt resolution of symptoms and encouraging results have also been reported in uncontrolled or retrospective trials. ${ }^{165-176}$ 
What lessons learned from the previous SARS-CoV and MERS-CoV viruses have proven useful to identify therapeutic targets for COVID-19?

These zoonotic beta-coronaviruses share structural and genomic similarities that are useful to understand COVID-19. SARS-CoV and MERS-CoV have lower transmission rate, shorter incubation time and higher fatality rates than SARS-CoV-2. In all of them, the spike protein plays a key role in infection via ACE2binding, hence it is a clear therapeutic target. Potential treatments already used for SARS-CoV and MERS$\mathrm{CoV}$ include remdesivir, chloroquine, tocilizumab and $\mathrm{CP}$, among others. However, none of them have been tested in robust clinical trials(see below section 8 ). Lessons in epidemiological surveillance and isolation measures have also proven useful. ${ }^{177}$

What is the impact of nonsteroidal anti-inflammatory drugs use in symptomatic COVID-19 patients?

Fang et al ..$^{178}$ suggested that there is ACE2 overexpression upon treatment with ACE inhibitors, thiazolidinediones and ibuprofen. There were concerns pertaining to the use of nonsteroidal anti-inflammatory drugs in COVID-19 patients. The European Medicines Agency clarified that no scientific evidence established a link between ibuprofen, or other nonsteroidal anti-inflammatory drugs, and a risk to worsen COVID-19. ${ }^{179}$

\section{Section 7: Clinical trials and drug discovery in COVID-19}

What are the main recommendations for organizing clinical trials during the COVID-19 pandemic?

Adaptations for clinical trials during the pandemic must include all concerned parties such as patients, clinical research organizations, clinical trial units, ethical committees, regulatory authorities and sponsors. Major changes must be approved by the responsible ethical committee and covered by the Informed Consent Form. Additional risks to participants should be addressed in the benefit-risk assessment section of the protocol, together with risk reduction measures. ${ }^{108}$ Patients who continue study participation should postpone site visits or, whenever possible, be replaced by remote data assessment via telemedicine under strict observation of data protection regulations. If needed, the duration of stay in the clinic should be limited and travel arranged to include alternatives to local public transport. The initiation of new clinical trials should be critically evaluated. The International Committee of Medical Journal Editors has clarified that in the event of public health emergencies such as COVID-19, information relevant for the public health should be disseminated because this would not preclude subsequent publication in a scientific journal. ${ }^{118}$

What are the main recommendations for clinical trial design during the COVID-19 pandemic?

Hundreds of registered clinical trials regarding potential therapies for COVID-19 are currently open in international registries. The study designs and outcomes are often divergent and based on a single center's experience or compassionate use of the candidate treatments. To improve the quality of the evidence and secondary analysis, the scientific community should lead multi-center, multi-arm and highly powered clinical trials and foster the global sharing of knowledge on the COVID-19. This approach would empower the generation of high-quality data on efficacy and safety of potential therapies for COVID-19. ${ }^{180}$

What are the main drugs under investigation that block SARS-CoV-2 cell entry?

There are drugs that interfere with ACE2 and TMPRSS2, which are molecules used by the virus to enter the cell. ${ }^{9,181}$ For example, camostat mesylate is a clinically proven serine protease inhibitor with affinity for TMPRSS2. It has shown activity against SARS-CoV-2 in human lung Calu-3 cells. ${ }^{9}$ Several drugs that target virus internalization are being investigated, including chloroquine phosphate and hydroxychloroquine, which have shown limited efficacy in humans and raised concerns due to side effects (see questions below ). ${ }^{163,182}$ A combination of cepharanthine (an anti-inflammatory alkaloid), selamectin (an avermectin used as an anti-helminthic and parasiticide drug in veterinary medicine) and mefloquine hydrochloride (used for the prophylaxis and treatment of malaria), ${ }^{183}$ and meplazumab ${ }^{184}$ (see questions below ), among others. Although still at the experimental level, a clinical-grade human recombinant ACE2 has shown efficacy to block SARS-CoV-2 growth in kidney epithelial cells (Vero cells) (Figure. 1 ). ${ }^{185}$

What are the main drugs under investigation that block SARS-CoV-2 replication? 
Drugs designed to inhibit the viral replication machinery may be effective against SARS-CoV-2. For example, remdesivir inhibits viral RNA polymerases, which prevents SARS-CoV-2 replication. In a cohort of severe COVID-19 patients, compassionate-use of remdesivir showed clinical improvement in $68 \%$ of patients (36 out of 53). ${ }^{186}$ Of note, a double-blind, randomized, placebo-controlled trial of intravenous remdesivir was conducted in 1,063 adults hospitalized with COVID-19 with evidence of lower respiratory tract involvement; remdesivir was superior to placebo in shortening the time to recovery in adults hospitalized with COVID-19 and evidence of lower respiratory tract infection. ${ }^{187}$ Furthermore, in a study of 5 HIV-positive hospitalized patients with severe COVID-19, 3 of them were given lopinavir-boosted ritonavir and 2 darunavir-boosted cobicistat for 14 days. Four patients recovered and 1 remained hospitalized. ${ }^{188}$ In another study with 99 hospitalized adult patients with severe COVID-19, no benefit beyond standard care was observed with lopinavir-boosted ritonavir treatment twice daily for 14 days. ${ }^{189}$ It is uncertain whether lopinavir-boosted ritonavir and other antiretrovirals improve clinical outcomes or prophylaxis among patients at high risk of SARS-CoV-2 infection. ${ }^{190}$ Additional potential candidates include other broad-spectrum antiviral drugs such as arbidol and favipiravir and phytochemicals with anti-viral activity such as resveratrol (Figure. 1 ). ${ }^{183}$

Is meplazumab a potential therapy for COVID-19 patients?

Meplazumab is a CD147-specific humanized monoclonal antibody that has been shown to prevent SARSCoV-2 infection of fibroblasts (VeroE6 cells). ${ }^{59}$ Currently, there is insufficient evidence to draw any conclusions on the benefits of meplazumab for the therapy of COVID-19 patients. In an observational Chinese study, adults hospitalized with COVID-19 pneumonia $(n=17)$ who were treated with an intravenous infusion of meplazumab as an add-on therapy showed a higher recovery rate compared to controls $(\mathrm{n}=11){ }^{184}$ However, these results should be interpreted with caution because they were generated in a non-randomized, non-stratified study, with a small sample size. Large-scale stuides are needed to assess the effectiveness and safety profile of meplazumab as a potential therapy for COVID-19.

Is CP therapy a therapeutic option for severe COVID-19 infection?

CP therapy for COVID-19 treatment has yielded promising results. For example, in a trial of 10 severe COVID-19 patients, ${ }^{191} \mathrm{CP}$ therapy was well tolerated and improved the clinical outcomes. The viral load was undetectable after CP transfusion in 7 patients who had viremia. No severe adverse effects were observed. Other clinical trials have shown the beneficial effect of CP therapy in COVID-19 patients and ongoing clinical trials will provide additional data on its efficacy, safety and optimal timing for treatment (Table 2 ). In this regard, it is unclear whether in patients with a high viral load, such as severely ill patients, CP therapy may drive tissue pathology through immune complexes or complement activation.

Do Janus kinase inhibitors represent a therapeutic option for severe COVID-19?

Baricitinib, fedratinib, and ruxolitinib are potent and selective JAK-STAT signaling inhibitors approved for indications such as rheumatoid arthritis and myelofibrosis. These drugs are powerful anti-inflammatory medications that may reduce the systemic levels of cytokines associated with COVID-19. ${ }^{192}$ Indeed, in a pilot study of 12 COVID-19 patients, baricitinib limited the CSS and was beneficial for the patients. ${ }^{193}$

What is the therapeutic value of ivermectin for treating SARS-CoV-2 infection?

Ivermectin (avermectin B1a and avermectin B1b) is an anti-parasitic drug that has shown broad-spectrum anti-viral activity in vitro. In SARS-CoV-2-infected fibroblasts (Vero-hSLAM cells), a single addition of Ivermectin at $2 \mathrm{~h}$ post-infection reduced viral RNA 5000 -fold at 48 hours. ${ }^{194}$ However, plasma concentrations of total and unbound ivermectin did not reach the IC50 determined in vitro, even at a 10-times higher dose than approved by the Food and Drug Administration (USA). ${ }^{195}$ Consequently, the likelihood of a successful clinical trial using ivermectin is low.

What is the evidence that hydroxychloroquine is effective for the treatment, or prophylaxis, of SARS-CoV-2 infection?

In an observational study of 1,446 COVID-19 patients, 811 received hydroxychloroquine treatment, which 
did not change the risk of intubation or death. ${ }^{196}$ Furthermore, in a Brazilian randomized control study evaluating 2 different doses of chloroquine in COVID-19 patients with severe respiratory symptoms, mortality was 2.5 times higher in the high-dose chloroquine arm. ${ }^{197}$ A recent study of 96,032 hospitalized patients with COVID-19 was unable to confirm a benefit of hydroxychloroquine or chloroquine, when used alone or with a macrolide, on in-hospital outcomes for COVID-19. ${ }^{182}$ Importantly, each of these drug regimens was associated with decreased in-hospital survival and an increased frequency of ventricular arrhythmias when used for treatment of COVID-19. ${ }^{182}$ Moreover, pre-published results from US Veterans Health Administration Hospitals did not support any advantages of hydroxychloroquine administered alone or with azithromycin. ${ }^{198}$

What is the evidence for mesenchymal stem cell therapy in COVID-19 patients?

Mesenchymal stem cells may exert antiviral mechanisms in the context of SARS-CoV-2 infection. The basal IFN-stimulated gene expression of mesenchymal stem cells is high. This enhances MSC responsiveness to IFN signaling, potentially inducing broad viral resistance. Mesenchymal stem cell therapy is being used in some centers but its efficacy in COVID-19 has not been proven. Data available are mainly experimental with few records in humans and no reports on its efficacy in randomized clinical trials. ${ }^{199}$

Are common anti-hypertensive drugs useful in the prevention and treatment of COVID-19? Common antihypertensive drugs inhibit ACE, but not ACE2. Importantly, ACE2 opposes ACE actions and lowers blood pressure by converting angiotensin-II (a vasoconstrictor peptide) into its metabolites- angiotensin (1-7) (vasodilators). ${ }^{200}$ Other common related antihypertensive drugs are angiotensin-2 receptors blockers, which block AT-1, a receptor for angiotensin-II, through which it exerts its vasoconstrictor effect. However, AT-1 is not known to be used by SARS-CoV-2 to infect cells. It was shown in animal models that ACE inhibitors might increase ACE2 expression, thus increasing susceptibility to infection. It has not been proven in humans but it raised the concerns during the COVID-19 pandemic ${ }^{200}$. Based on the data available to date, antihypertensive treatment with these medications should be continued. ${ }^{201}$

What are the preclinical models available to investigate SARS-CoV-2 infection? Which ones resemble human COVID-19 the most?

At the moment, the animal model that resembles more closely human COVID-19 is the Rhesus macaque, whose ACE2 receptor is identical to that in humans. This model recently showed that SARS-CoV-2 reinfection was hampered due to infection-acquired immunity and demonstrated the therapeutic effect of remdesivir in COVID-19 prior use in human clinical trials (Bao L 2020; Williamson 2020). The murine ACE2 receptor is different from humans, hence humanized murine models with recombinant human ACE2 are necessary. ${ }^{202}$

\section{Section 8: Vaccine development for COVID-19}

What are the most advanced vaccine candidates for COVID-19?

Previous vaccine research for SARS/MERS facilitates rapid translation. ${ }^{203}$ In the WHO vaccine platform, 110 candidate vaccines are in preclinical evaluation and 8 candidate vaccines are in clinical evaluation for SARS-CoV-2 (adenovirus type 5 vector; LNP-encapsulated mRNA; Inactivated; ChAdOx1; 3 LNP-mRNAs; DNA plasmid vaccine with electroporation) as of May 15, 2020. ${ }^{204}$ The Coalition for Epidemic Preparedness Innovations provides dynamic status updates (https://cepi.net).

The thermal and chemical stability of single-domain antibodies position them as a potential therapy for viral infections. Could this approach be applied in COVID-19?

SARS-CoV, MERS-CoV and SARS-CoV-2 are zoonotic pathogens. SARS-CoV spike protein-directed singledomain antibodies cross-react with SARS-CoV-2 and MERS-CoV. In recent research, immunization of llamas with perfusion-stabilized spike-proteins of betacoronavirus induced bivalent cross-reactive single-domain camelid antibodies that could neutralize SARS-CoV-2 pseudoviruses. Crystallography has revealed that single-domain antibodies impede viral penetration into cells. The favorable biophysical and potent neutralization properties support the possibility of therapeutic use. ${ }^{205}$ Human monoclonal antibodies may offer similar neutralization capacity with potential for better tolerability and a longer half-life. ${ }^{206}$ 
Given that SARS-CoV-2 is predominantly a respiratory pathogen, could a nebulized vaccine be more effective in terms of bioavailability and function?

Single-domain antibodies have been investigated as potential therapeutics for influenza, RSV and HIV in addition to coronaviruses. SARS-CoV-2 mainly targets the respiratory tract, hence the development of vaccines directed to the respiratory epithelia and lung parenchyma using a nebulizer has been considered to maximize bioavailability and function. ${ }^{207}$ Although active research against respiratory viruses has focused on aerosolized plasmid DNA vaccines, other forms of vaccine administration are currently further advanced in clinical trials. ${ }^{203}$ Veterinary medicine commonly uses aerosolized coronavirus vaccines for chicken farms. ${ }^{208}$

When will a SARS-CoV-2 vaccine be available?

A novel vaccine platform requires careful evaluation and should ideally include toxicological studies in valid animal models. Early progress towards SARS vaccines has facilitated a "running start" but standards of care and safety must be maintained. Acceleration rather than omission of clinical trials is key. Preliminary data from Oxford University is anticipated by mid-2020. ${ }^{203}$ Of note, a dose-escalation, single-center, openlabel, non-randomized, phase 1 was conducted in 108 healthy individuals that received an Ad5 vectored COVID-19 vaccine. The vaccine was tolerable and immunogenic at 28 days post-vaccination. SARS-CoV-2specific antibodies peaked at day 28 post-vaccination and specific T-cell responses were detected from day 14 post-vaccination. ${ }^{209}$

\section{Section 9: Epidemiology of COVID-19 and environmental factors}

What are some characteristic aspects of the COVID-19 pandemic?

An important aspect is that COVID-19-associated mortality is very high, almost unavoidable when the pandemic control fails. This is due to rapid community spread, high community virus, especially in the elderly and co-morbid, but also in younger non-comorbid persons, including healthcare workers, young adults and children. The COVID-19 pandemic also seems to be characterized by a significant level of asymptomatic spread. ${ }^{210-212}$

The iceberg of COVID-19: are there asymptomatic cases below the surface?

The number of COVID-19 diagnosed patients may represent just the tip of the iceberg. To date, epidemiological studies that provide an accurate idea of asymptomatic cases are scarce. ${ }^{4,5,93}$ Most of the identified asymptomatic cases are diagnosed by random screening of healthcare workers, and individuals who had been in close contact with COVID-19 cases. ${ }^{49}$ In addition, there is a high number of asymptomatic individuals who have experienced COVID-19-like symptoms in their clinical histories without any diagnostic tests and hospital admission. Due to the nature of this disease, it is difficult to identify asymptomatic virus carriers and it is one of the challenges faced in the containment of the pandemic. ${ }^{5}$ The real percentage of asymptomatic individuals and how long they carry the virus is unknown. Large screening studies for virus-specific $\operatorname{IgM}$, IgG and IgA will be a decisive factor in controlling the pandemic, as it is the main indicator of the development of population immunity.

What are the reasons for striking differences in the COVID-19 infection rate among countries with similar climate, lifestyle and location at similar latitude?

The differences are almost entirely due to the timing and effectiveness of public health interventions. Countries that failed to control did too little, too late, and allowed SARS-CoV-2 to rip through their population, with catastrophic outcomes. Those that intervened early effectively stopped the disease transmission. ${ }^{213}$

What is the basic reproduction number (R0) of SARS-CoV-2?

It is difficult to determine as it varies greatly from country to country, depending on how well countries control their epidemics with widespread testing, case isolation and vigorous contact tracing, testing and isolation if positive. In countries that do this well, the R0 can be very low indeed. In countries that fail to 
control the spread of the virus, the R0 is high but unknown as SARS-CoV-2 spreads untested and therefore undetected. It has been estimated to be ${ }^{\sim} 2.2 .^{214}$

What differentiates the previous epidemiological distribution of SARS- CoV-1 and MERS-CoV to the current SARS-CoV-2?

SARS-CoV-2 transmits more readily than either SARS-CoV or MERS-CoV. The R0 of SARS-CoV-2 is controversial but if left unchecked it is likely to be greater than 3-4. However, the R0 number cannot be precisely defined as no country has left it to spread completely unchecked. In any case, even when preventative measures are taken, the R0 of SARS-CoV-2 is higher than that of SARS-CoV (1.7-1.9) and MERS-CoV $(<1) .{ }^{215}$ There is a considerable frequency of very mild COVID-19 patients as well as asymptomatic SARSCoV-2-infected people. This makes transmission control more challenging than either SARS-CoV or MERS$\mathrm{CoV}$, where illness is frequently more severe.

Are children at risk of SARS-CoV-2 infection?

Children are at low risk of severe COVID-19 outcomes. ${ }^{216,217}$ Most patients in pediatric age with SARSCoV2 infection presented with no or mild clinical manifestations, including fever, fatigue and dry cough. They were typically managed with supportive treatments only and they had generally a favorable prognosis with a recovery within 2 weeks. ${ }^{218-220}$

\section{Are children involved in SARS-CoV-2 transmission?}

Many children remain asymptomatic, even when they have radiologic pneumonia detected on screening. ${ }^{216}$ Given that children are effective transmitters of other respiratory viruses ${ }^{221}$ it is expected that they will be just as good at transmitting SARS-CoV-2.

Which animals in nature have been so far shown to get infected with SARS-CoV-2?

Bats are likely the natural reservoir of SARS-CoV-2. In addition, related coronaviruses have been identified in Malayan pangolins, which are considered as an intermediate host between bats and humans. SARS-CoV-2 replicates poorly in dogs, pigs, chickens, and ducks, but ferrets, cats and Rhesus macaques are permissive to infection. ${ }^{222}$

What demographic factors are associated with severe COVID-19?

Data on the characteristics of severe COVID-19 patients are uniformly showing a correlation with age. According to the CDC National Vital Statistic System on COVID-19 fatal outcomes, death rate doubles with each decade after 45 years (National Vital Statistics System). Comorbidities have also been associated with more severe disease ${ }^{14}$. In Italy ${ }^{223}$ and $\mathrm{China}^{224}$ hypertension (OR 2.36), chronic respiratory disease (OR 2.46), cardiovascular disease (OR 3.42) and diabetes (OR 2.05) show a positive correlation with severity. Gender and ethnicity have also been shown to impact COVID-19 severity (see questions below ).

Does ethnicity influence the prevalence of SARS-CoV-2 infection?

Data on ethnicity and COVID-19 are scarce and further research on ethnicity and COVID-19 outcomes is needed. ${ }^{225}$ However, the data available show a disproportionate number of COVID-19 deaths in Black, Asian and minority ethnic backgrounds. In fact, one third of UK ICU admissions are reportedly from them. ${ }^{226}$ In the USA, African Americans had more COVID-19 diagnoses and deaths, after adjusting for age, poverty, comorbidities, and epidemic duration. These disparities are also seen in the Hispanic and Asian communities. ${ }^{227}$

Are pregnant women at risk of COVID-19 infection?

Pregnant women may be at a higher risk of poorer COVID-19 outcomes because they have deficient IFN- $\alpha$ and IFN- $\lambda$ responses to viral infections. ${ }^{228}$ However, reported pregnancy outcomes in COVID-19 are reassuring as they appear similar to non-pregnant adult females. ${ }^{229}$

Are there specific treatments for pregnant women in case of severe COVID-19? 
Testing treatments is problematic because pregnant women are excluded from most trials. ${ }^{230}$ It is known that azithromycin doubles innate IFN production from virus-infected lung cells. ${ }^{231}$ It is safe for all trimesters of pregnancy ${ }^{232}$ and has been shown effective in high-quality clinical trials of virus-induced lung disease. ${ }^{233,234}$

Are males at a greater risk of SARS-CoV-2 infection?

Given that the human ACE2 protein is encoded on the X chromosome, this may be relevant for male-female differences in outcomes. Particularly in males with rare ACE2 coding variants as they will express those variants in all ACE2-expressing cells compared to a mosaic pattern of expression in females. ${ }^{235}$

Males may also have differences in certain innate antiviral responses compared to female counterparts. ${ }^{236}$ Outcomes in COVID-19 can be worse ( ${ }^{\sim} 1.5-4$ times worse) in terms of mortality, ICU admissions, hospitalisations ${ }^{95,237,238}$ and case identifications ${ }^{239}$ for males than for females. Mortality in females can be lower by $30 \%$ up to age 60 in certain (but not all) countries. Outcomes after 60 years of age seem to continue unbalanced between the sexes. ${ }^{240,241}$

How long will it take to generate robust and reliable data on COVID-19 prevalence?

There is reasonably robust data of COVID-19 deaths in hospitals because most people who die in hospital are tested. Deaths outside hospitals are likely underestimated as people are dying in care homes where mortality approaches $\sim 40 \%,{ }^{242}$ and may die without being tested and diagnosed. It is difficult to determine prevalence as testing practices vary so much from country to country. Seroprevalence studies will help to collect these data.

Is COVID-19 prevalence higher in industrialized countries?

COVID-19 was introduced rapidly to many industrialized countries as a result of air travel. Most of Europe and the USA probably did not react in a timely and efficient manner, resulting in the rapid spread and subsequent high mortality rates. In light of the devastating situation in many European countries and the USA, less industrialized countries had a little more time to better prepare to control the pandemic. ${ }^{243} \mathrm{An}$ important factor for prevalence studies is the percentage of the population that has undergone a diagnostic test, which seems to be at lower levels in developing countries.

Will the summer weather decrease the SARS-CoV-2 spread?

Respiratory viruses spread less readily in summer than in winter for reasons that are not well understood. Dry air and higher temperatures are slowing down the spread of respiratory viruses. Absence of school attendance, more time outdoors, greater household ventilation, warmer temperatures facilitating virus inactivation and higher vitamin D levels are all likely to play a part. Although social distancing measures are implemented, the summer weather should play a role in hampering the spread of COVID-19. However, based on the analogy of previous influenza pandemic, it is unlikely that summer, on its own, could stop transmission of SARS-CoV-2. ${ }^{244,245}$

Is a second wave of COVID-19 expected to occur?

It largely depends on the SARS-CoV-2 seroprevalence developed in each country, which is still unknown. Countries that have had widespread transmission may be hit by a second wave, but presumably with less severe consequences. Countries that effectively controlled the pandemic are at a higher risk of second wave of COVID-19 if those effective controls are relaxed due to the limited viral transmission and lack of active immunization.

What is the evidence suggesting that SARS-CoV-2 could become a seasonal infection rather than a transient pandemic?

SARS-CoV-2 has spread worldwide in humans, causing mild or no disease in many cases. It will continue circulating similar to other human coronaviruses (229E, HKU1, NL63, OC43), and it may well become an endemic, seasonal virus. ${ }^{246}$ 
What is the most efficient strategy to prevent SARS-CoV-2 infection?

The main route of SARS-CoV-2 transmission is via respiratory droplets and aerosols. ${ }^{247-249}$ Avoidance of high virus loads, acquired through aerosol and droplet transmission, is paramount to prevent severe outcomes. Consequently, social distancing, masks and hand sanitation are undoubtedly effective because they prevent the droplet and surface contact-associated initial high virus load and the increased risk of severe disease. ${ }^{250,251}$ The COVID-19 pandemic can be controlled if social distancing is combined with widespread testing, case isolation, vigorous contact tracing and personal protection. Indeed, severe and critical illness among Chinese healthcare workers before January $10^{\text {th }}$ was $45 \%$, a time when personal protection equipment and infectious control measures were likely not implemented. After February $1^{\text {st }}$, when personal protection measures were in place, the percentage of severe and critically ill Chinese healthcare workers dropped to $8.7 \%{ }^{252}$

What is the relative risk to contract SARS-CoV-2 infection through surfaces?

SARS-CoV-2 remained viable in aerosols for $3 \mathrm{~h}$ with a $~ 10$-fold reduction in infectious titre. ${ }^{253}$ SARS-CoV-2 was more stable on plastic and stainless steel than on copper and cardboard; viable virus was detected up to 3 days after application to plastic and 2 days to stainless steel, on each surface the virus titer was reduced nearly 100 -fold. ${ }^{253}$ Therefore, it is convenient to minimize contact with surfaces touched by others (even before SARS-CoV-2 existed), for example when using public transportation.

What is the duration of viral shedding?

In 248 COVID-19 patients, the estimated median time from symptom onset to viral clearance in the nasal swabs was 11 days, while in asymptomatic cases it was 2 days. ${ }^{254}$ In patients that recovered, the median duration of viral shedding was 20 days, while in non-survivors it was detected until death. The longest duration of viral shedding in survivors was 37 days. ${ }^{95}$ In addition, non-SARS-CoVs have been shown to be carried in the human respiratory tract without any current infection, ${ }^{255}$ this type of carrier may serve as a silent reservoir of SARS-CoV-2, thus contributing to its transmission. Cai et al. analyzed the clinical characteristics of 298 patients with confirmed COVID-19 and found that a slow viral clearance is associated with an increased risk of high disease severity with a $1 \%$ mortality rate..$^{256}$

Do some COVID-19 patients act as "superspreaders"?

The individual variation in the transmission of an infection is described by a factor called "dispersion factor or $k$ ". The lower " $k$ " value, the more transmission comes from a small proportion of individuals acting like superspreaders. Superspreading clusters have been observed in past coronavirus outbreaks (SARS/MERS), where a small number of infected individuals was responsible for a large proportion of secondary transmissions, with an estimated " $k$ " of about 0.16 for SARS and 0.25 for MERS. ${ }^{257}$ It is unclear whether superspreading clusters have contributed to the COVID-19 outbreak. A simulation of early outbreak trajectories estimated that " $k$ " for COVID-19 is higher than for SARS and MERS. ${ }^{257}$ However, in a recent preprint study, the estimate of " $k$ " for SARS-CoV-2 was around 0.1 , suggesting that around $10 \%$ of infected patients may have been responsible for $80 \%$ of secondary transmissions. ${ }^{258}$ Individual variation in infectiousness is difficult to measure, as it is mostly empirical, but the identification of any SARS-CoV-2 superspreading will be of primary importance for pandemic control.

Are COVID-19-dedicated hospitals useful to limit SARS-CoV-2 infections and optimize the healthcare resources during the COVID-19 pandemic?

The designation of COVID-19-dedicated wards and personnel within hospitals is useful to limit nosocomial SARS-CoV-2 infections. ${ }^{108}$ It also allows other non-COVID-19 conditions to be treated using routine healthcare resources more safely and effectively. Maintaining such separation requires intensive SARS-CoV-2 testing in view of the high asymptomatic infection rate. ${ }^{259}$

Is a community-based strategy more effective, in comparison to a hospital-based one, to limit SARS-CoV-2 infections and optimize healthcare resources during the COVID-19 pandemic? 
Community-based strategies are effective at controlling the transmission of SARS-CoV-2. Australia, Hong Kong, Japan, Singapore, South Korea, and New Zealand have all controlled effectively. Their cumulative COVID-19 mortality is $>100$-fold less than that in Belgium, France, Italy, Spain and the UK, countries which have had difficulties to adequately control the pandemic. ${ }^{260-262}$ It is important to implement measures to contain the spread of the virus, such as developing models to predict SARS-CoV-2-related mortality. ${ }^{263}$

May the elimination of the live animal market reduce the risk of future viral outbreaks?

Closing live animal markets is likely to reduce the risk of future viral outbreaks although this is not a practical way to prevent viral outbreaks for multiple reasons including social and economic.

Are new technologies (geolocation, phone apps, etc.) useful to track people during quarantine?

This is an evolving area with a rapidly expanding interest. Many countries around the world are considering or are developing mobile phone apps capable of supporting rapid contact tracing as well as supporting and monitoring social distancing. ${ }^{264}$ Their usefulness is yet to be proven, and there are privacy and ethical considerations that require open debate and careful planning. ${ }^{265}$

What kind of lifestyle factors play a role in the COVID-19 pandemic?

Lifestyle factors that may influence SARS-CoV-2 infection susceptibility and COVID-19 severity include smoking, stress, diet and alcohol intake, among others. For example, smoking has been shown to increase the susceptibility to respiratory tract infections and its severity, ${ }^{266}$ and it is a risk factor for severe COVID-19. ${ }^{267}$ Moreover, alcohol consumption may impair anti-viral immunity; ${ }^{268}$ in vitro studies with human monocytes have shown that both acute and prolonged alcohol exposures inhibit type I IFN induction upon Toll-like receptor- 8 and -4 stimulation ${ }^{269}$. Dietary habits may also play a role as obese patients have been shown to have a higher risk of developing severe COVID-19. ${ }^{270}$ Furthermore, there are bioactive food compounds with antiviral activity, such as resveratrol, ${ }^{271}$ although the amount of them obtained through the diet is unlikely to play a relevant role in COVID-19.

Could the higher cleaning and disinfectant exposure during the pandemic increase the allergy prevalence in the general population?

It is well-established that epithelial barrier defects and/or damage favor the development of Th2 immunity. ${ }^{272,273}$ Increased hygiene, in general, as well as overexposure to epithelial barrier opening molecules, such as detergents, can promote the onset of allergic disease. ${ }^{274}$ To date, there is no evidence linking the COVID-19 protective measures (gloves, hand-sanitizers,etc. ) with increased allergy prevalence. In this regard, multifactorial epidemiological studies are needed. These studies should consider the impact on allergic diseases of virus-specific type 1 responses and psychosocial and environmental changes caused by the pandemic and efforts to contain it.

The COVID-19 pandemic has reduced fossil fuels and environmental pollution. Could this change the exposome in the long term and alter the cause of allergic and other respiratory diseases?

Although there has been a significant change in pollution parameters, unfortunately this reduction in pollution is transient and consequently unlikely to be significant. The exposome-related allergy and asthma risk is multifactorial. It includes climate change, biodiversity, the microbiome and nutrition among others, which have not changed during the pandemic. ${ }^{275}$ In addition, although pollution levels have dropped, climate change still occurs at an accelerated pace. Lifestyle changes during the lockdown ${ }^{276}$, weight gain and increased exposure to indoor allergens and pollutants may even increase the incidence of allergic diseases in the long-run.

\section{Conclusion}

With the rapid spread of COVID-19 at a pandemic scale, we are overwhelmed and drowned with a wealth of information. A global fight to contain the pandemic has started in which we need international solidarity and prompt sharing of accurate scientific information. We strongly support the implementation of an open 
data concept for all COVID-19 studies, which should be performed with full transparency. A global strategy to reduce the burden of COVID-19 must be established. It is well known that these action plans can only be successful by combining efforts from stakeholders: WHO, governments, researchers, physicians, patient organizations, economists, pharmacists, industry, and policy makers. There is a pressing need to develop and implement global and regional COVID-19 guidelines on all aspect of this disease. The EAACI has immediately taken action on disseminating knowledge and developing official statements ${ }^{44,108,116,118}$ on how to handle allergy and asthma patients during the COVID-19 pandemic. As evidence on the epidemiology, course and treatment of the disease is exponentially increasing, all the recommendations made by EAACI need to be regularly updated and amended in line with up-coming evidence.

Authorship: CA, RJS, CR, PC and MG conceptualized and designed the structure of the manuscript. CA, RJS, CR, PC, MG and DA prepared figures and tables. All the authors contributed to the manuscript, revised and edited. CR, RJS and CA orchestrated the whole process and conducted the final editing.

Financial support: MCvZ, is supported by an NHMRC Senior Research Fellowship (GNT1117687); IEG is supported by the Instituto de Salud Carlos III from the Spanish Ministry of Economy and Competitiveness through the "Juan Rodes" funding scheme for IEG (JR19/0029); RJS is supported by Ministerio de Economía y Competitividad (IJCI-2016-27619).

Conflicts of interest : IA serves as associate editor of Allergy. JB reports personal fees from Chiesi, Cipla, Hikma, Menarini, Mundipharma, Mylan, Novartis, Sanofi-Aventis, Takeda, Teva, Uriach, KYomed-Innov and Purina, outside the submitted work; DCis an employee of a Clinical Research Organization; ZD reports that in the past 3 years has acted as Executive and Scientific Medical Director at a phase I/II pharmacological unit (QPS-NL), which performs clinical studies for pharmaceutical companies; received honoraria, consultancy and speaker fees from Acucort, Astrazeneca, ALK, Aquilon, Boehringer Ingelheim, CSL, HAL Allergy, MSD, Sanofi-Genzyme; TEreports grants from DBV, Innovation fund Denmark, CIHR, Regeneron; TE is the Co-I or scientific lead in three investigator initiated oral immunotherapy trials including the usage of biologicals supported by the Allergy and Anaphylaxis Program, Sickkids, and CIHR; TE serves as associate editor for Allergy and is on the advisory board for ALK;WF , reports grants and personal fees from Sanofi, Novartis, and grants from GSK, Mylan, ALK and Allergy Therapeutics, outside the submitted work; SLJ reports personal fees from Virtus Respiratory Research, Myelo Therapeutics GmbH, Concert Pharmaceuticals, Bayer, Synairgen, Novartis, Boehringer Ingelheim, Chiesi, Gerson Lehrman Group, resTORbio, Bioforce, Materia Medical Holdings, PrepBio Pharma, Pulmotect, Virion Health, Lallemand Pharma, AstraZeneca, outside the submitted work; SLJ has these patents: Wark PA, Johnston SL, Holgate ST, Davies DE. Anti-virus therapy for respiratory diseases. UK patent application No. GB 0405634.7, 12 March 2004. with royalties paid; Wark PA, Johnston SL, Holgate ST, Davies DE. Interferon-Beta for Anti-Virus Therapy for Respiratory Diseases. International Patent Application No. PCT/ GB05/50031, 12 March 2004. with royalties paid; Davies DE, Wark PA, Holgate ST, Johnston SL. Interferon Lambda therapy for the treatment of respiratory disease. UK patent application No. 6779645.9, granted 15th August 2012. licensed; MJ reports personal fees from ALK-Abello, Allergopharma, Stallergenes, Anergis, Allergy Therapeutics, Circassia, Leti, Biomay and HAL during the conduct of the study; personal fees from Astra-Zeneka, GSK, Novartis, Teva, Vectura, UCB, Takeda, Roche, Janssen, MedImmune and Chiesi, outside the submitted work; LK reports grants and personal fees from Allergopharma, MEDA/Mylan, Sanofi, LETI Pharma; personal fees from HAL Allergie and Allergy Therapeut; grants from ALK Abelló, Stallergenes, Quintiles, ASIT biotech, Lofarma, AstraZeneca, GSK and Inmunotek outside the submitted work; is a member of AeDA, DGHNO, Deutsche Akademie für Allergologie und klinische Immunologie, HNO-BV GPA and EAACI; LOM reports personal fees from AHL and grants from GSK outside the submitted work;KN , reports grants from National Institute of Allergy and Infectious Diseases (NIAID), Food Allergy Research \& Education (FARE), End Allergies Together (EAT), Allergenis, and Ukko Pharma; Grant awardee at NIAID, National Institute of Environmental Health Sciences (NIEHS), National Heart, Lung, and Blood Institute (NHLBI), and the Environmental Protection Agency (EPA); is involved in Clinical trials with Regeneron, Genentech, Aimmune Therapeutics, DBV Technologies, AnaptysBio, Adare Pharmaceuticals, and Stallergenes-Greer; Research Sponsorship by Novartis, Sanofi, Astellas, Nestle; Data and Safety Monitoring Board member at Novartis and NHLBI; Cofounded 
Before Brands, Alladapt, ForTra, and Iggenix; Chief Intellectual Office at FARE, Director of the World Allergy Organization (WAO) Center of Excellence at Stanford, Personal fees from Regeneron, AstraZeneca, ImmuneWorks, and Cour Pharmaceuticals; Consultant and Advisory Board Member at Ukko, Before Brands, Alladapt, IgGenix, Probio, Vedanta, Centecor, Seed, Novartis, NHBLI, EPA, National Scientific Committee of ITN and NIH Programs; US patents (patent numbers 62/647,389; 62/119,014; 12/610,940, 12/686,121, 10/064,936, 62/767,444; application numbers S10-392); OP reports grants and personal fees from ALK-Abelló, Allergopharma, Stallergenes Greer, HAL Allergy Holding B.V./HAL Allergie GmbH, Bencard Allergie GmbH/Allergy Therapeutics, Lofarma, ASIT Biotech Tools S.A., Laboratorios LETI/LETI Pharma, Anergis S.A.; grants from Biomay and Circassia; personal fees from MEDA Pharma/MYLAN, Mobile Chamber Experts (a GA2LEN Partner), Indoor Biotechnologies, Glaxo Smith Kline, personal fees from Astellas Pharma Global, EUFOREA, ROXALL, NOVARTIS, SANOFI AVENTIS, Med Update Europe GmbH, streamedup! GmbH, outside the submitted work; JSreports personal fees from MYLAN and F2F events, outside the submitted work; and industry support to educational activities of the Scottish Allergy and Respiratory Academy and of the Children's and Young people's Allergy Networtk Scotland; industry support to EAACI; JS serves as EAACI Secretary General (2019-2021); MSo reports grants from Swiss National Science Foundation and GSK, outside the submitted work;CA reports grants from Allergopharma, Idorsia, Swiss National Science Foundation, Christine Kühne-Center for Allergy Research and Education, European Commission's Horizon's 2020 Framework Programme, Cure, Novartis Research Institutes, Astra Zeneca, Scibase, Glakso Smith-Kline and other from Sanofi \& Regeneron. All other authors have no conflict of interest within the scope of the submitted work.

Acknowledgements : The authors thank the European Academy of Allergy and Clinical Immunology (EAACI) for the support to the Junior Member Assembly (JMA), the sections, interest groups and working groups that enabled the generation of this paper. The authors recognize Dr. Anna Globinska for graphic design and Dr. Laura Alberch for a critical review of the manuscript.

\section{Tables 1}

Table 1. Lymphopenia is associated with disease severity in COVID-19 patients. Adapted from Azkur et al 49

\begin{tabular}{lll}
\hline Blood Lymphocyte (\%) & $\begin{array}{l}\mathbf{1}^{\text {st }} \text { Time point (10-12 days } \\
\text { after symptom } \text { onset) }\end{array}$ & $\begin{array}{l}\mathbf{2}^{\text {nd }} \text { Time point (17-19 days } \\
\text { after symptom onset) }\end{array}$ \\
\hline$>20 \%$ & Mild / Moderate disease & Recovering group \\
$5-20 \%$ & Severe disease & At risk group \\
$<5 \%$ & Severe disease & Critically ill group \\
\hline
\end{tabular}

Table 2: Convalescent plasma studies in COVID-19 patients as of $21^{\text {th }}$ May 2020

\begin{tabular}{lllll}
\hline Study & Subjects & Design & Dose & Outcomes
\end{tabular}




$\begin{array}{llll}\text { Duan K, et al. }{ }^{191} & \text { 10 Severe disease, } & \text { Pilot study, single } & \text { 200 ml CP with } \\ \text { China } & \text { ICU no MV } & \text { center. Compared } & \text { neutralizing } \\ & \text { to historic control } & \text { antibody titers } \\ & \text { group } & >1: 640\end{array}$

Shen C, et al. ${ }^{277}$

China

Zhang B, et al. ${ }^{278}$

China

Ahn JY, et al. ${ }^{279}$

South Korea

Ye M, et al. ${ }^{280}$

China

Zeng QL et al. ${ }^{281}$ China
5 Critical disease, all in ICU + MV

4 Critical disease, $\mathrm{ICU}+\mathrm{MV}$

2 Critical disease, $\mathrm{ICU}+\mathrm{MV}$

6 Non-critically ill

Case series

21 ICU patients 6 : active CP 15:

controls series

Case series
Uncontrolled. Case series, single center

Uncontrolled. Case

$250 \mathrm{ml}, 2$ doses $12 \mathrm{~h}$ specify neutralizing
Case series Nonrandomized.Controls did not have a match for CP apart, (does not antibody titer)

200 - $600 \mathrm{ml} \mathrm{CP}$ (does not specify neutralizing antibody titer) 200 - $400 \mathrm{ml} \mathrm{CP}$ (does not specify neutralizing antibody titer)

$400 \mathrm{ml} \mathrm{CP}$ with titer $>1: 1000$ and

200 - 400 ml CP (does not specify neutralizing antibody titer) neutralizing
Increase in neutralizing antibodies.

Improvement of symptoms. Increase in oxyhemoglobin saturation at d 3 . Decrease CRP. No severe side effects. Reduction of deaths compared to historic control (p 0.001 )

4/5: ARDS resolved within 12 d $5 / 5$ :

Pao2/Fio2 increased within 12 d 5/5:

SARS-CoV-2 RNA load negative at $\mathrm{d}$ $123 / 5$ : discharged from hospital at date of publication (51-55 d post infusion) 4/4 clinical improvement and able to extubate $3 / 4$ discharged from hospital at date of publication (24-33 d post infusion)

Radiological and clinical improvement. Decrease in viral load Radiological and clinical improvement

Increase in viral clearance in the $\mathrm{CP}$ vs controls. [CP $5 / 5$, Controls 3/14 (p 0.005)] Increase survival period in $\mathrm{CP}$ patients ( $\mathrm{p}$ 0.029 ) but there was high mortality in both groups, [CP $5 / 6$, controls 14/15] 


\begin{tabular}{|c|c|c|c|c|}
\hline $\begin{array}{l}\text { Schulman K. (PI) } \\
\text { USA }\end{array}$ & $\begin{array}{l}\text { Estimated } \\
\text { enrollment: } 206 \\
\text { patients visiting the } \\
\text { ED }\end{array}$ & $\begin{array}{l}\text { Phase } 2 \text { trial. } \\
\text { Randomized, double } \\
\text { blinded, controlled. } \\
\text { CP vs placebo in } \\
\text { adults with } \\
\text { COVID-19 in an ED }\end{array}$ & $\begin{array}{l}200-600 \mathrm{ml} \mathrm{CP} \\
\text { with neutralizing } \\
\text { antibody titers } \\
>1: 80\end{array}$ & $\begin{array}{l}\text { Stanford University } \\
\text { Ongoing } \\
\text { NCT04355767 }\end{array}$ \\
\hline $\begin{array}{l}\text { Shoham S. (PI) } \\
\text { USA }\end{array}$ & $\begin{array}{l}\text { Estimated } \\
\text { enrollment: } 150 \\
\text { subjects exposed to } \\
\text { COVID-19 }\end{array}$ & $\begin{array}{l}\text { Phase } 2 \text { trial. } \\
\text { Randomized, triple } \\
\text { blinded, controlled. } \\
\text { CP vs placebo. } \\
\text { Adults in close } \\
\text { contact exposure to } \\
\text { a person with } \\
\text { COVID-19 within } \\
96 \mathrm{~h} \text { of enrollment } \\
\text { (and } 120 \mathrm{~h} \text { of } \\
\text { receipt of plasma) }\end{array}$ & $\begin{array}{l}200 \mathrm{ml} \mathrm{CP} \text { with } \\
\text { neutralizing } \\
\text { antibody titers } \\
>1: 64\end{array}$ & $\begin{array}{l}\text { Johns Hopkins } \\
\text { University Ongoing } \\
\text { NCT04323800 }\end{array}$ \\
\hline Perotti C. (PI) Italy & $\begin{array}{l}\text { Estimated } \\
\text { enrollment: } 46 \\
\text { COVID-19 patients } \\
\text { with } \\
\text { moderate-severe } \\
\text { ARDS for }<10 \mathrm{~d} \\
\text { and need for MV }\end{array}$ & $\begin{array}{l}\text { Longitudinal } \\
\text { non-randomized } \\
\text { non-controlled }\end{array}$ & $\begin{array}{l}250-300 \mathrm{ml} \text { of } \mathrm{CP} 3 \\
\text { times/d over } 5 \mathrm{~d} \\
\text { (neutralizing } \\
\text { antibody titer not } \\
\text { specified) }\end{array}$ & $\begin{array}{l}\text { Foundation IRCCS } \\
\text { San Matteo } \\
\text { Hospital Ongoing } \\
\text { NCT04321421 }\end{array}$ \\
\hline $\begin{array}{l}\text { Menichetti F. (PI) } \\
\text { Italy }\end{array}$ & $\begin{array}{l}\text { Estimated } \\
\text { enrollment: } 126 \\
\text { COVID- } 19 \text { patients } \\
\text { hospitalized due to } \\
\text { pneumonia with } \\
\mathrm{PaO}_{2} / \mathrm{FiO}_{2} \text { ratio } \\
200-350 \text { but not in } \\
\mathrm{MV}\end{array}$ & $\begin{array}{l}\text { Phase } 2 \text { Trial. } \\
\text { Multicenter } \\
\text { prospective } \\
\text { randomized } \\
\text { open-label trial }(\mathrm{CP} \\
\text { vs standard therapy }\end{array}$ & $\begin{array}{l}200 \mathrm{ml} \text { of } \mathrm{CP} \\
\text { (neutralizing } \\
\text { antibody titer not } \\
\text { specified) }\end{array}$ & $\begin{array}{l}\text { Azienda } \\
\text { Ospedaliero, } \\
\text { Universitaria Pisana } \\
\text { Ongoing } \\
\text { NCT04393727 }\end{array}$ \\
\hline
\end{tabular}

ARDS , Acute respiratory distress syndrome; CP , Convalescent plasma; CRP , C- reactive protein; d , days; ED , Emergency department; h , hours;ICU , Intensive Care Unit; PI , Principal investigator;MV , mechanical ventilation.

Table 3. Recommendations for AIT during the COVID-19 pandemic. Based on EAACI-ARIA guidelines ${ }^{118}$

Continue SCIT or SLIT:

Non-infected individuals Asymptomatic patient without suspicion for SARS-CoV-2 infection and/or contact with SARS-CoV-2 positive individuals Patients recovered after COVID-19 infection Patient with negative test result (RT-PCR) Patient after an adequate quarantine Patient with serum IgG to SARS-CoV-2 without virus-specific IgM

Stop SCIT or SLIT Symptomatic patients with exposure or contact to SARS-CoV-2 positive individuals Patients with positive test results (RT-PCR) 
AIT , allergen immunotherapy; SCIT , subcutaneous immunotherapy; SLIT , sublingual immunotherapy; RT-PCR, reverse transcription polymerase chain reaction.

\section{Figure Legends}

Figure 1. SARS-CoV-2 attachment, internalization and replication cycle in epithelial cells and the main effect of antiviral agents. Attachment of SARS-CoV-2 spike protein (S) to angiotensin-converting enzyme 2 (ACE2) mediates endocytosis of the virus into the host cell. The cell entry of the virus depends on both the binding of viral $\mathrm{S}$ proteins to cellular receptors and priming $\mathrm{S}$ protein by the serine protease transmembrane protease / serine (TMPRSS) 2. Cepharanthine / human recombinant ACE2 and camostat mesylate are the viral entry inhibitors, which prevent the binding of S protein to ACE2 and priming, respectively. In the uncoating stage, virions are internalized by receptor-mediated endocytosis that the low $\mathrm{pH}$ in the endosome triggers the fusion of viral and endosomal membranes and the ssRNA (+) viral genome is released into the cytoplasm. Arbidol, chloroquine, hydroxychloroquine, and mefloquine block this uncoating stage. Transcription of the viral genome and proteolytic cleavage of the replicase polyprotein and resulting translating proteins are processed into the viral RNA-dependent RNA polymerase (RdRp). Lopinavir, ritonavir, remdesivir and favipiravir prevent proteolysis and activity of RdRp. Non-structural and structural proteins, including nucleocapsid proteins are expressed as sub-genomic RNAs. Salemectin and resveratrol may inhibit viral helicase activity, viral mRNA synthesis and the expression of nucleocapsid proteins. Assembly and budding of viral proteins and nucleocapsid occur at membranes of the endoplasmic reticulum (ER), the ER-Golgi intermediate compartment (ERGIC), and/or the Golgi complex. New SARS$\mathrm{CoV}-2$ virions are released by exocytosis.

Figure 2. Diagnosis of SARS-CoV-2 infection through different diagnostic tests over time according to incubation period, disease onset, clinical disease and convalescence.

Figure 3. Preventive measures for SARS-CoV-2 infection and control for healthcare providers. PPE, personal protective equipment (medical mask, eye/facial protection, gloves, long sleeve gown and waterproof apron). *Adequately ventilated room: natural ventilation with airflow of at least $160 \mathrm{~L} / \mathrm{s}$ per patient, or negative-pressure rooms with at least 12 air changes per hour. Controlled direction of airflow when using mechanical ventilation (adapted from "WHO: Infection prevention and control during health care when COVID-19 is suspected"). ${ }^{111}$

Figure 4. Organization of an allergy clinic during the COVID-19 pandemic. Patients should be triaged to determine those in need of face-to-face consultation and those at risk of infection with SARS-CoV-2. Telehealth should be prioritized in allergy clinics. Procedures at high risk of generating airborne particles should be avoided. Patients should be motivated to notify their healthcare professionals in case of exacerbations or changes in their usual symptoms.

Figure 5. Practical considerations for allergy therapies during the COVID-19 pandemic. Continuation of second generation H1-antihistamines for the treatment of allergic rhinitis and urticaria, topical corticosteroids for atopic dermatitis, nasal corticosteroids for allergic rhinitis, and inhaled corticosteroids for asthma. Subcutaneous immunotherapy (SCIT) and sublingual immunotherapy (SLIT) for respiratory and venom allergies should be continued in non-infected individuals and patients recovered from COVID-19 and it should be suspended in patients diagnosed with COVID-19 or suspected of SARS-CoV-2 infection until resolution of COVID-19 is established. Biologicals should be continued, if possible as home self-administration, in patients non-infected or recovered from COVID-19 and they should be suspended in patients diagnosed with COVID-19 or suspected of SARS-CoV-2 infection until resolution of COVID-19 is established.

Figure 6 . Cutaneous manifestations of COVID-19. Several skin manifestations can be potentially associated with the disease: 1) local skin inflammation is often connected with the antibody response toward viral nucleotides and presents as morbilliform rash, maculopapular lesions, vesicular exanthems, urticaria and erythema multiforme; 2) systemic inflammation is associated with vasculitis and thrombosis which shows as peripheral cyanosis, livedo reticularis and chilblain-like lesions; 3) hypersensitivity reactions to drugs may occur more often during the pandemic due to the increased use of drugs and drug interactions, which can 
result in morbilliform rash, erythroderma, exanthematous pustulosis and anaphylaxis.

\section{Figure 1}
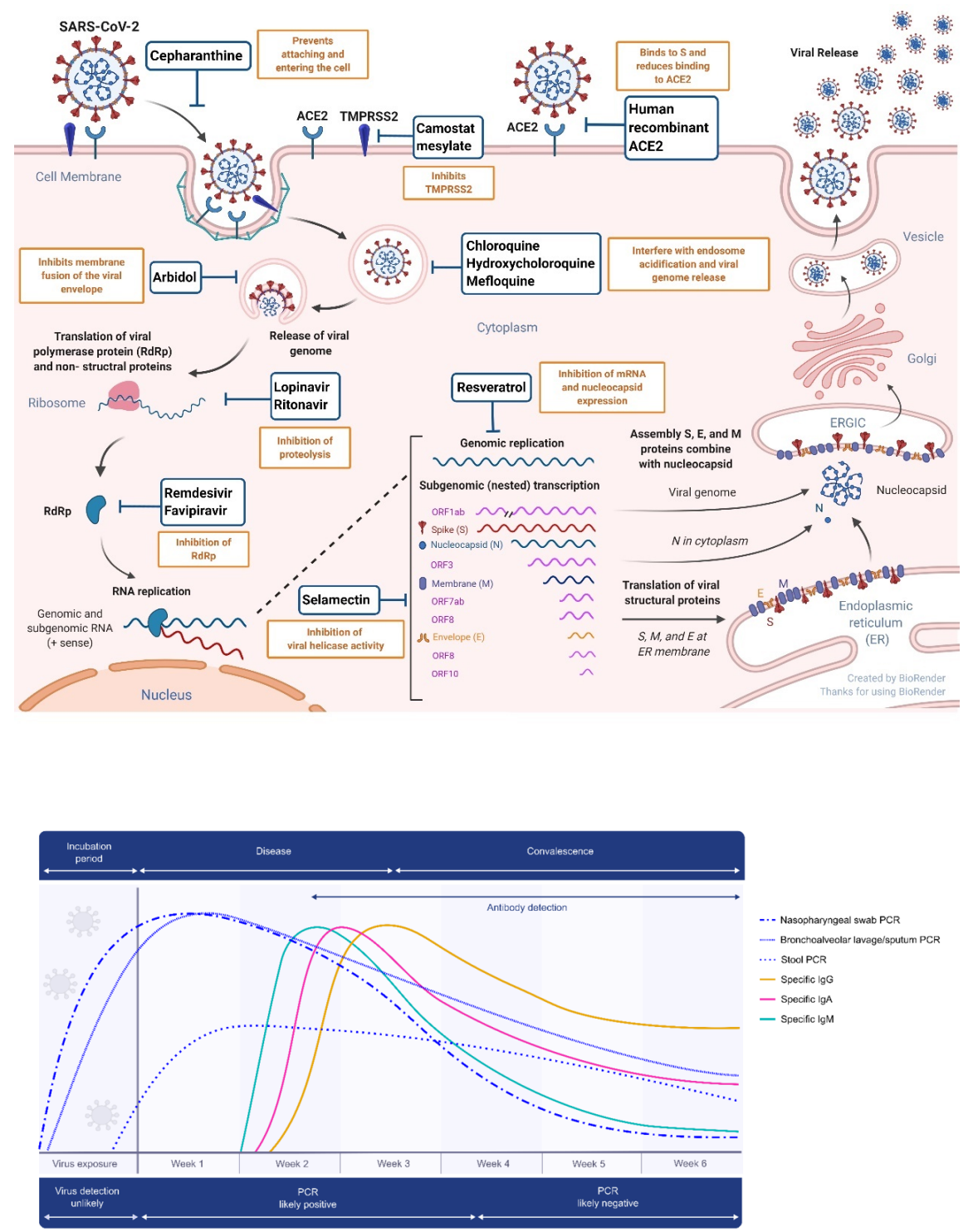

Figure 


\begin{tabular}{|l|l|l|l|}
\hline \multicolumn{3}{|c|}{$\begin{array}{l}\text { Measures for SARS-CoV-2 infection prevention } \\
\text { and control for health care providers }\end{array}$} \\
\hline $\begin{array}{l}\text { Measures } \\
\text { for patients }\end{array}$
\end{tabular}

\section{Figure 3}

Organization of an allergy clinic during the COVID-19 pandemic

1. Prioritize the use of telehealth in delivering allergy/immunology services
(e.g. video, chat, email, internet, remote monitoring)
2. Select the patients needing direct consultation based on proper screening
protocols for prevention of disease spread
3void and re-schedule high-risk procedures:
- Lung function testing (i.e. spirometry, FeNO, IOS, bronchial provocation test)
- Nasal provocation test, rhinoscopy and nasal citology
Initiation or updosing of any food Immunotherapy
or Motivate patients to notify their healthcare professionals in case of exacerbation

Figure 4 .

Figure 5 
Practical considerations for allergy therapies during COVID-19

\begin{tabular}{|c|c|c|}
\hline Therapies & $\begin{array}{l}\text { Non-infected or recovered } \\
\text { from COVID-19 }\end{array}$ & $\begin{array}{l}\text { COVID-19 diagnosed } \\
\text { or suspected } \\
\text { of SARS-CoV-2 infection }\end{array}$ \\
\hline $\begin{array}{l}\text { Second-generation } \mathrm{H} 1 \text {-antihistamines } \\
\text { for allergic rhinitis and urticaria }\end{array}$ & Continue & Continue \\
\hline $\begin{array}{l}\text { Topical corticosteroids } \\
\text { for atopic dermatitis }\end{array}$ & Continue & Continue \\
\hline $\begin{array}{l}\text { Nasal corticosteroids } \\
\text { for allergic rhinitis }\end{array}$ & Continue & Continue \\
\hline $\begin{array}{l}\text { Inhaled corticosteroids } \\
\text { for asthma }\end{array}$ & Continue & Continue \\
\hline $\begin{array}{l}\text { SCIT or SLIT } \\
\text { for allergic rhinitis, asthma } \\
\text { or venom allergy }\end{array}$ & Continue & $\begin{array}{l}\text { Stop until COVID-19 } \\
\text { resolution is established }\end{array}$ \\
\hline Biologicals & $\begin{array}{c}\text { Continue } \\
\text { (if possible as home } \\
\text { self-administration) }\end{array}$ & $\begin{array}{l}\text { Stop until COVID-19 } \\
\text { resolution is established }\end{array}$ \\
\hline
\end{tabular}

\section{Cutaneous manifestations of COVID-19}

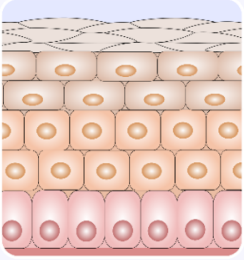

1. Local skin inflammation

$\rightarrow$ Circulating antibodies - response to viral nucleotides

- Morbilliform rash

- Maculopapular lesions

- Vesicular exanthems

- Urticaria

- Erythema multiforme

2. Systemic inflammation

$\rightarrow$ Vasculitis - thrombosis

- Peripheral cyanosis (bullae-dry gangrene)

- Petechial rash

- Livedo reticularis

- Chilblain-like lesions

3. Drug hypersensitivity

$\rightarrow$ Increased risk of adverse reactions - increased risk of drug interactions

- Morbiliform rash

- Erythroderma

- Exanthematous pustulosis

- Anaphylaxis

Figure 6. 


\section{References}

1. Li Q, Guan X, Wu P, et al. Early Transmission Dynamics in Wuhan, China, of Novel Coronavirus-Infected Pneumonia. N Engl J Med.2020;382(13):1199-1207.

2. WHO. Coronavirus disease (COVID-2019) situation reports. 2020; https://www.who.int/emergencies/diseases/novel-coronavirus-2019/situation-reports. Accessed May $28,2020$.

3. Tsang TK, Wu P, Lin Y, Lau EHY, Leung GM, Cowling BJ. Effect of changing case definitions for COVID-19 on the epidemic curve and transmission parameters in mainland China: a modelling study.Lancet Public Health. 2020;5(5):e289-e296.

4. Bai Y, Yao L, Wei T, et al. Presumed Asymptomatic Carrier Transmission of COVID-19. JAMA. 2020.

5. Dong X, Cao YY, Lu XX, et al. Eleven faces of coronavirus disease 2019. Allergy. 2020.

6. Andersen KG, Rambaut A, Lipkin WI, Holmes EC, Garry RF. The proximal origin of SARS-CoV-2. Nat Med. 2020;26(4):450-452.

7. Forster P, Forster L, Renfrew C, Forster M. Phylogenetic network analysis of SARS-CoV-2 genomes. Proc Natl Acad Sci U S A.2020;117(17):9241-9243.

8. Wang Q, Zhang Y, Wu L, et al. Structural and Functional Basis of SARS-CoV-2 Entry by Using Human ACE2. Cell. 2020;181(4):894-904 e899.

9. Hoffmann M, Kleine-Weber H, Schroeder S, et al. SARS-CoV-2 Cell Entry Depends on ACE2 and TMPRSS2 and Is Blocked by a Clinically Proven Protease Inhibitor. Cell. 2020;181(2):271-280 e278.

10. Radzikowska U, Ding M, Tan G, et al. Distribution of ACE2, CD147, cyclophilins, CD26 and other SARS-CoV-2 associated molecules in various human tissues and immune cells in health and disease. Submitted.2020.

11. Sungnak W, Huang N, Becavin C, et al. SARS-CoV-2 entry factors are highly expressed in nasal epithelial cells together with innate immune genes. Nat Med. 2020;26(5):681-687.

12. Ziegler CGK, Allon SJ, Nyquist SK, et al. SARS-CoV-2 Receptor ACE2 Is an Interferon-Stimulated Gene in Human Airway Epithelial Cells and Is Detected in Specific Cell Subsets across Tissues. Cell. 2020.

13. Qi F, Qian S, Zhang S, Zhang Z. Single cell RNA sequencing of 13 human tissues identify cell types and receptors of human coronaviruses.Biochem Biophys Res Commun. 2020;526(1):135-140.

14. Radzikowska U, Ding M, others a, Sokolowska M. Distribution of ACE2, CD147, cyclophilins, CD26 and other SARS-CoV-2 associated molecules in various human tissues and immune cells in health and disease.Allergy. 2020.

15. Whitworth KM, Rowland RRR, Petrovan V, et al. Resistance to coronavirus infection in amino peptidase N-deficient pigs. Transgenic Res. 2019;28(1):21-32.

16. Holmes RS, Spradling-Reeves KD, Cox LA. Mammalian Glutamyl Aminopeptidase Genes (ENPEP) and Proteins: Comparative Studies of a Major Contributor to Arterial Hypertension. J Data Mining Genomics Proteomics. 2017;8(2).

17. Itoyama S, Keicho N, Quy T, et al. ACE1 polymorphism and progression of SARS. Biochem Biophys Res Commun. 2004;323(3):1124-1129.

18. Trouillet-Assant S, Viel S, Gaymard A, et al. Type I IFN immunoprofiling in COVID-19 patients. $J$ Allergy Clin Immunol.2020. 
19. Chu H, Chan JF, Wang Y, et al. Comparative replication and immune activation profiles of SARS-CoV-2 and SARS-CoV in human lungs: an ex vivo study with implications for the pathogenesis of COVID-19.Clin Infect Dis. 2020.

20. DeDiego ML, Nieto-Torres JL, Jimenez-Guardeno JM, et al. Coronavirus virulence genes with main focus on SARS-CoV envelope gene. Virus Res. 2014;194:124-137.

21. Karamloo F, Konig R. SARS-CoV-2 immunogenicity at the crossroads.Allergy. 2020;n/a(n/a).

22. Zhang JJ, Dong X, Cao YY, et al. Clinical characteristics of 140 patients infected with SARS-CoV-2 in Wuhan, China. Allergy. 2020.

23. Joob B, Wiwanitkit V. SARS-CoV-2 and HIV. J Med Virol.2020;n/a(n/a).

24. Shah B, Modi P, Sagar SR. In silico studies on therapeutic agents for COVID-19: Drug repurposing approach. Life Sci.2020;252:117652.

25. Lu J, Cui J, Qian Z, et al. On the origin and continuing evolution of SARS-CoV-2. National Science Review. 2020.

26. Su Y, Anderson D, Young B, et al. Discovery of a 382-nt deletion during the early evolution of SARSCoV-2. bioRxiv. 2020.

27. Zheng S, Fan J, Yu F, et al. Viral load dynamics and disease severity in patients infected with SARSCoV-2 in Zhejiang province, China, January-March 2020: retrospective cohort study. BMJ.2020;369:m1443.

28. Pan Y, Zhang D, Yang P, Poon LLM, Wang Q. Viral load of SARS-CoV-2 in clinical samples. Lancet Infect Dis. 2020;20(4):411-412.

29. Xiao F, Tang M, Zheng X, Liu Y, Li X, Shan H. Evidence for Gastrointestinal Infection of SARS-CoV-2. Gastroenterology.2020;158(6):1831-1833 e1833.

30. Tian Y, Rong L, Nian W, He Y. Review article: gastrointestinal features in COVID-19 and the possibility of faecal transmission. Aliment Pharmacol Ther. 2020;51(9):843-851.

31. Woo PC, Lau SK, Wong BH, et al. Longitudinal profile of immunoglobulin G (IgG), IgM, and IgA antibodies against the severe acute respiratory syndrome (SARS) coronavirus nucleocapsid protein in patients with pneumonia due to the SARS coronavirus. Clin Diagn Lab Immunol. 2004;11(4):665-668.

32. Mo H, Zeng G, Ren X, et al. Longitudinal profile of antibodies against SARS-coronavirus in SARS patients and their clinical significance. Respirology. 2006;11(1):49-53.

33. Long QX, Liu BZ, Deng HJ, et al. Antibody responses to SARS-CoV-2 in patients with COVID-19. Nat Med. 2020.

34. Wang B, Wang L, Kong X, et al. Long-term coexistence of SARS-CoV-2 with antibody response in COVID-19 patients. J Med Virol. 2020.

35. Yongchen Z, Shen H, Wang X, et al. Different longitudinal patterns of nucleic acid and serology testing results based on disease severity of COVID-19 patients. Emerg Microbes Infect. 2020;9(1):833-836.

36. Huang AT, Garcia-Carreras B, Hitchings MDT, et al. A systematic review of antibody mediated immunity to coronaviruses: antibody kinetics, correlates of protection, and association of antibody responses with severity of disease. medRxiv.2020:2020.2004.2014.20065771.

37. Grzelak L, Temmam S, Planchais C, et al. SARS-CoV-2 serological analysis of COVID-19 hospitalized patients, pauci-symptomatic individuals and blood donors. medRxiv.2020:2020.2004.2021.20068858.

38. Carsetti R, Quintarelli C, Quinti I, et al. The immune system of children: the key to understanding SARS-CoV-2 susceptibility? The Lancet Child $\&$ Adolescent Health. 2020;4(6):414-416. 
39. Nickbakhsh S, Mair C, Matthews L, et al. Virus-virus interactions impact the population dynamics of influenza and the common cold.Proc Natl Acad Sci U S A. 2019.

40. Hamming I, Timens W, Bulthuis ML, Lely AT, Navis G, van Goor H. Tissue distribution of ACE2 protein, the functional receptor for SARS coronavirus. A first step in understanding SARS pathogenesis. $J$ Pathol. 2004;203(2):631-637.

41. Bunyavanich S, Do A, Vicencio A. Nasal Gene Expression of Angiotensin-Converting Enzyme 2 in Children and Adults. JAMA.2020.

42. Wen W, Su W, Tang H, et al. Immune cell profiling of COVID-19 patients in the recovery stage by single-cell sequencing. Cell Discov. 2020;6:31.

43. Kwok KO, Lai F, Wei WI, Wong SYS, Tang JWT. Herd immunity - estimating the level required to halt the COVID-19 epidemics in affected countries. J Infect. 2020;80(6):e32-e33.

44. Vultaggio A, Agache I, Akdis CA, et al. Considerations on Biologicals for Patients with allergic disease in times of the COVID-19 pandemic: an EAACI Statement. Allergy. 2020.

45. Blauvelt A, Simpson EL, Tyring SK, et al. Dupilumab does not affect correlates of vaccine-induced immunity: A randomized, placebo-controlled trial in adults with moderate-to-severe atopic dermatitis. $J$ Am Acad Dermatol. 2019;80(1):158-167 e151.

46. Jackson DJ, Busse WW, Bacharier LB, et al. Association of respiratory allergy, asthma, and expression of the SARS-CoV-2 receptor ACE2. J Allergy Clin Immunol. 2020;in press.

47. Dhawale VS, Amara VR, Karpe PA, Malek V, Patel D, Tikoo K. Activation of angiotensin-converting enzyme 2 (ACE2) attenuates allergic airway inflammation in rat asthma model. Toxicol Appl Pharmacol.2016;306:17-26.

48. Roisman GL, Danel CJ, Lacronique JG, Alhenc-Gelas F, Dusser DJ. Decreased expression of angiotensinconverting enzyme in the airway epithelium of asthmatic subjects is associated with eosinophil inflammation. J Allergy Clin Immunol. 1999;104(2 Pt 1):402-410.

49. Azkur AK, Akdis M, Azkur D, et al. Immune response to SARS-CoV-2 and mechanisms of immunopathological changes in COVID-19. Allergy.2020.

50. Lindsley AW, Schwartz JT, Rothenberg ME. Eosinophil responses during COVID-19 infections and coronavirus vaccination. J Allergy Clin Immunol. 2020.

51. Barton LM, Duval EJ, Stroberg E, Ghosh S, Mukhopadhyay S. COVID-19 Autopsies, Oklahoma, USA. Am J Clin Pathol. 2020;153(6):725-733.

52. Brockow K, Ardern-Jones MR, Mockenhaupt M, et al. EAACI position paper on how to classify cutaneous manifestations of drug hypersensitivity. Allergy. 2019;74(1):14-27.

53. Jesenak M, Schwarze J. Lung eosinophils-A novel "virus sink" that is defective in asthma? Allergy. 2019;74(10):1832-1834.

54. Jesenak M, Banovcin P, Diamant Z. COVID-19, chronic inflammatory respiratory diseases and eosinophils - Observationsfrom reported clinical case series. Allergy. 2020;n/a(n/a).

55. Zhang M, Guogang, X., Fengming, D.; Han, L; Dongning, Y.; Hongzhou, L. The role of peripheral blood eosinophil counts in COVID-19Allergy. 2020.

56. Hassani M, Leijte G, Bruse N, et al. Differentiation and activation of eosinophils in the human bone marrow during experimental human endotoxemia. J Leukoc Biol. 2020.

57. Du Y, Tu L, Zhu P, et al. Clinical Features of 85 Fatal Cases of COVID-19 from Wuhan: A Retrospective Observational Study. Am J Respir Crit Care Med. 2020. 
58. Huang C, Wang Y, Li X, et al. Clinical features of patients infected with 2019 novel coronavirus in Wuhan, China. Lancet.2020;395(10223):497-506.

59. Ulrich H, Pillat MM. CD147 as a Target for COVID-19 Treatment: Suggested Effects of Azithromycin and Stem Cell Engagement. Stem Cell Rev Rep. 2020:1-7.

60. Herbinger KH, Hanus I, Beissner M, et al. Lymphocytosis and Lymphopenia Induced by Imported Infectious Diseases: A Controlled Cross-Sectional Study of 17,229 Diseased German Travelers Returning from the Tropics and Subtropics. Am J Trop Med Hyg.2016;94(6):1385-1391.

61. Qu R, Ling Y, Zhang YH, et al. Platelet-to-lymphocyte ratio is associated with prognosis in patients with coronavirus disease-19.J Med Virol. 2020.

62. Grifoni A, Weiskopf D, Ramirez SI, et al. Targets of T cell responses to SARS-CoV-2 coronavirus in humans with COVID-19 disease and unexposed individuals. Cell. 2020.

63. Ng OW, Chia A, Tan AT, et al. Memory T cell responses targeting the SARS coronavirus persist up to 11 years post-infection. Vaccine.2016;34(17):2008-2014.

64. Diao B, Wang C, Tan Y, et al. Reduction and Functional Exhaustion of T Cells in Patients With Coronavirus Disease 2019 (COVID-19).Front Immunol. 2020;11:827.

65. Ma Y, Jiang J, Gao Y, et al. Research progress of the relationship between pyroptosis and disease. Am $J$ Transl Res.2018;10(7):2213-2219.

66. Tan L, Wang Q, Zhang D, et al. Lymphopenia predicts disease severity of COVID-19: a descriptive and predictive study. Signal Transduct Target Ther. 2020;5(1):33.

67. Tisoncik JR, Korth MJ, Simmons CP, Farrar J, Martin TR, Katze MG. Into the eye of the cytokine storm. Microbiol Mol Biol Rev.2012;76(1):16-32.

68. Behrens EM, Koretzky GA. Review: Cytokine Storm Syndrome: Looking Toward the Precision Medicine Era. Arthritis Rheumatol.2017;69(6):1135-1143.

69. Ye Q, Wang B, Mao J. The pathogenesis and treatment of the 'Cytokine Storm' in COVID-19. J Infect. 2020;80(6):607-613.

70. Prompetchara E, Ketloy C, Palaga T. Immune responses in COVID-19 and potential vaccines: Lessons learned from SARS and MERS epidemic.Asian Pac J Allergy Immunol. 2020;38(1):1-9.

71. Yang Y, Shen C, Li J, et al. Exuberant elevation of IP-10, MCP-3 and IL-1ra during SARS-CoV-2 infection is associated with disease severity and fatal outcome. medRxiv. 2020:2020.2003.2002.20029975.

72. Ritchie AI, Singanayagam A. Immunosuppression for hyperinflammation in COVID-19: a double-edged sword? Lancet. 2020;395(10230):1111.

73. Poston JT, Patel BK, Davis AM. Management of Critically Ill Adults With COVID-19. JAMA. 2020.

74. Matthay MA, Aldrich JM, Gotts JE. Treatment for severe acute respiratory distress syndrome from COVID-19. Lancet Respir Med.2020;8(5):433-434.

75. Brough HA, Kalayci O, Sediva A, et al. Managing childhood allergies and immunodeficiencies during respiratory virus epidemics - the 2020 COVID-19 pandemic. Pediatr Allergy Immunol. 2020.

76. Qin C, Zhou L, Hu Z, et al. Dysregulation of immune response in patients with COVID-19 in Wuhan, China. Clin Infect Dis. 2020.

77. Michalovich D, Rodriguez-Perez N, Smolinska S, et al. Obesity and disease severity magnify disturbed microbiome-immune interactions in asthma patients. Nat Commun. 2019;10(1):5711. 
78. Wu Q, Zhou L, Sun X, et al. Altered Lipid Metabolism in Recovered SARS Patients Twelve Years after Infection. Sci Rep.2017;7(1):9110.

79. Huppert LA, Matthay MA, Ware LB. Pathogenesis of Acute Respiratory Distress Syndrome. Semin Respir Crit Care Med. 2019;40(1):31-39.

80. Ackermann M, Verleden SE, Kuehnel M, et al. Pulmonary Vascular Endothelialitis, Thrombosis, and Angiogenesis in Covid-19. N Engl J Med. 2020.

81. Sokolowska M LZ, Agache and others, Untersmayer, E. Immunology of COVID-19: mechanisms, clinical outcome, diagnostics and perspectives - a report of the 1

European Academy of Allergy and Clinical Immunology (EAACI) Submitted. 2020.

82. Gattinoni L, Chiumello D, Rossi S. COVID-19 pneumonia: ARDS or not? Crit Care. 2020;24(1):154.

83. Fan E, Brodie D, Slutsky AS. Acute Respiratory Distress Syndrome: Advances in Diagnosis and Treatment. JAMA. 2018;319(7):698-710.

84. Ozdemir C, Kucuksezer UC, Tamay ZU. Is BCG vaccination affecting the spread and severity of COVID19? Allergy. 2020;n/a(n/a).

85. Gursel M, Gursel I. Is global BCG vaccination-induced trained immunity relevant to the progression of SARS-CoV-2 pandemic? Allergy. 2020;n/a(n/a).

86. Hamiel U, Kozer E, Youngster I. SARS-CoV-2 Rates in BCG-Vaccinated and Unvaccinated Young Adults. JAMA. 2020.

87. Curtis N, Sparrow A, Ghebreyesus TA, Netea MG. Considering BCG vaccination to reduce the impact of COVID-19. Lancet.2020;395(10236):1545-1546.

88. WHO. Bacille Calmette-Guerin (BCG) vaccination and COVID-19. 2020; https://www.who.int/news$\mathrm{room} /$ commentaries/detail/bacille-calmette-gu\%C3\%A9rin-(bcg)-vaccination-and-covid-19. Accessed April $29,2020$.

89. Riphagen S, Gomez X, Gonzalez-Martinez C, Wilkinson N, Theocharis P. Hyperinflammatory shock in children during COVID-19 pandemic. Lancet. 2020;395(10237):1607-1608.

90. Verdoni L, Mazza A, Gervasoni A, et al. An outbreak of severe Kawasaki-like disease at the Italian epicentre of the SARS-CoV-2 epidemic: an observational cohort study. Lancet. 2020.

91. Viner RM, Whittaker E. Kawasaki-like disease: emerging complication during the COVID-19 pandemic. Lancet. 2020.

92. Terpos E, Ntanasis-Stathopoulos I, Elalamy I, et al. Hematological findings and complications of COVID-19. Am J Hematol. 2020.

93. Guan WJ, Ni ZY, Hu Y, et al. Clinical Characteristics of Coronavirus Disease 2019 in China. N Engl $J$ Med. 2020;382(18):1708-1720.

94. Lechner M, Chandrasekharan D, Jumani K, et al. Anosmia as a presenting symptom of SARS-CoV-2 infection in healthcare workers - A systematic review of the literature, case series, and recommendations for clinical assessment and management. Rhinology. 2020.

95. Zhou F, Yu T, Du R, et al. Clinical course and risk factors for mortality of adult inpatients with COVID-19 in Wuhan, China: a retrospective cohort study. Lancet. 2020;395(10229):1054-1062.

96. Sethuraman N, Jeremiah SS, Ryo A. Interpreting Diagnostic Tests for SARS-CoV-2. JAMA. 2020.

97. Nalla AK, Casto AM, Huang MW, et al. Comparative Performance of SARS-CoV-2 Detection Assays using Seven Different Primer/Probe Sets and One Assay Kit. J Clin Microbiol. 2020:JCM.00557-00520. 
98. Wang W, Xu Y, Gao R, et al. Detection of SARS-CoV-2 in Different Types of Clinical Specimens. JAMA. 2020.

99. WHO. Laboratory testing for 2019 novel coronavirus (2019-nCoV) in suspected human cases. 2020; https://www.who.int/publications-detail/laboratory-testing-for-2019-novel-coronavirus-in-suspectedhuman-cases-20200117 Accessed May 24, 2020.

100. Padoan A, Sciacovelli L, Basso D, et al. IgA-Ab response to spike glycoprotein of SARS-CoV-2 in patients with COVID-19: A longitudinal study. Clin Chim Acta. 2020;507:164-166.

101. Udugama B, Kadhiresan P, Kozlowski HN, et al. Diagnosing COVID-19: The Disease and Tools for Detection. ACS Nano.2020;14(4):3822-3835.

102. WHO. Advice on the use of point-of-care immunodiagnostic tests for COVID-19. 2020; https://www.who.int/news-room/commentaries/detail/advice-on-the-use-of-point-of-careimmunodiagnostic-tests-for-covid-19 Accessed May 24, 2020.

103. Pan Y, Li X, Yang G, et al. Serological immunochromatographic approach in diagnosis with SARSCoV-2 infected COVID-19 patients.J Infect. 2020.

104. Lu X, Wang L, Sakthivel SK, et al. US CDC Real-Time Reverse Transcription PCR Panel for Detection of Severe Acute Respiratory Syndrome Coronavirus 2. Emerg Infect Dis. 2020;26(8).

105. Zhang JJ, Cao YY, Dong X, et al. Distinct characteristics of COVID-19 patients with initial rRTPCR-positive and rRT-PCR-negative results for SARS-CoV-2. Allergy. 2020;n/a(n/a).

106. Control ECfDPa. Guidance for discharge and ending isolation in the context of widespread community transmission of COVID-19. 2020; https://www.ecdc.europa.eu/sites/default/files/documents/covid-19guidance-discharge-and-ending-isolation-first\%20update.pdf. Accessed May 21, 2020.

107. Malipiero G, Paoletti G, Puggioni F, et al. An academic allergy unit during COVID-19 pandemic in Italy. J Allergy Clin Immunol.2020.

108. Pfaar O KL, Jutel M, Akdis CA, Bousquet J, Breiteneder H, et al. . COVID-19 pandemic: Practical considerations on the organization of an allergy clinic - an EAACI/ARIA Position Paper. Allergy. 2020;In press.

109. Portnoy J, Waller M, Elliott T. Telemedicine in the Era of COVID-19. J Allergy Clin Immunol Pract. 2020;8(5):1489-1491.

110. Kiecolt-Glaser JK, Heffner KL, Glaser R, et al. How stress and anxiety can alter immediate and late phase skin test responses in allergic rhinitis. Psychoneuroendocrinology. 2009;34(5):670-680.

111. WHO. Infection prevention and control during health care when novel coronavirus (nCoV) infection is suspected. 2020; https://www.who.int/publications-detail/infection-prevention-and-control-during-healthcare-when-novel-coronavirus-(ncov)-infection-is-suspected-20200125. Accessed May 24, 2020.

112. Zhang Y, Zhang L. Management Practice of Allergic Rhinitis in China During the COVID-19 Pandemic. Allergy Asthma Immunol Res.2020;12(4):738-742.

113. CDC. Interim Guidelines for Biosafety and COVID-19. 2020; cdc.gov/coronavirus/2019-ncov/lab/labbiosafety-guidelines.html. Accessed May 24, 2020.

114. Hui Du XD, Jin-jin Zhang, Yi-yuan Cao, Mubeccel Akdis, Pei-qi Huang,Hong-wei Chen,Ying Li, Guang-hui Liu, Cezmi A Akdis, Xiao-xia Lu, Ya-dong Gao. Clinical characteristics of 182 pediatric COVID19 patients with different severities and allergic status. Allergy.2020.

115. OSHA. COVID-19 - Control and Prevention. 2020; https://www.osha.gov/SLTC/covid19/controlprevention.html. Accessed May 24, 2020. 
116. Bousquet J, Akdis C, Jutel M, et al. Intranasal corticosteroids in allergic rhinitis in COVID-19 infected patients: An ARIA-EAACI statement. Allergy. 2020.

117. Leonardi A, Fauquert JL, Doan S, et al. Managing ocular allergy in the time of COVID-19. Allergy. $2020 ; n / a(n / a)$.

118. Klimek L, Jutel M, Akdis C, et al. Handling of allergen immunotherapy in the COVID-19 pandemic: An ARIA-EAACI statement.Allergy. 2020.

119. Fokkens WJ, Lund VJ, Hopkins C, et al. European Position Paper on Rhinosinusitis and Nasal Polyps 2020. Rhinology. 2020;58(Suppl S29):1-464.

120. Pellegrino R, Cooper KW, Di Pizio A, Joseph PV, Bhutani S, Parma V. Corona Viruses and the Chemical Senses: Past, Present, and Future.Chem Senses. 2020.

121. Bilinska K, Jakubowska P, Von Bartheld CS, Butowt R. Expression of the SARS-CoV-2 Entry Proteins, ACE2 and TMPRSS2, in Cells of the Olfactory Epithelium: Identification of Cell Types and Trends with Age.ACS Chem Neurosci. 2020.

122. Hopkins C, Surda P, Whitehead E, Kumar BN. Early recovery following new onset anosmia during the COVID-19 pandemic - an observational cohort study. J Otolaryngol Head Neck Surg. 2020;49(1):26.

123. Van Gerven L, Hellings PW, Cox T, Fokkens WJ, Hopkins C. Personal protection and delivery of rhinologic and endoscopic skull base procedures during the COVID-19 outbreak: ERS endorsed advises. Rhinology. 2020;58(3).

124. WHO. Rational Use of Personal Protective Equipment for Coronavirus Disease 2019 (COVID19). 2020; https://apps.who.int/iris/bitstream/handle/10665/331215/WHO-2019-nCov-IPCPPE_use2020.1-eng.pdf. Accessed May 24, 2020.

125. WHO. Clinical management of severe acute respiratory infection when COVID-19 is suspected. 2020; https://www.who.int/publications-detail/clinical-management-of-severe-acute-respiratoryinfection-when-novel-coronavirus-(ncov)-infection-is-suspected. Accessed May 24, 2020.

126. Simon F, Haggard M, Rosenfeld RM, et al. International consensus (ICON) on management of otitis media with effusion in children.Eur Ann Otorhinolaryngol Head Neck Dis. 2018;135(1S):S33-S39.

127. Rosenfeld RM, Schwartz SR, Pynnonen MA, et al. Clinical practice guideline: Tympanostomy tubes in children. Otolaryngol Head Neck Surg. 2013;149(1 Suppl):S1-35.

128. Society BT. Advice for Healthcare Professionals Treating People with Asthma (adults)

in relation to COVID-19. 2020; https://www.brit-thoracic.org.uk/document-library/qualityimprovement/covid-19/bts-advice-for-healthcare-professionals-treating-patients-with-asthma/ Accessed May 21, 2020.

129. Moiseev S, Avdeev, S., Brovko, M. et al. . Low prevalence of bronchial asthma and chronic obstructive lung disease among intensive care unit patients with COVID-19. Allergy. 2020.

130. Farsi A, Carli, G., Cecchi, L. et al. . Is asthma proctective against COVID-19? 2020.

131. Peters MC, Sajuthi S, Deford P, et al. COVID-19 Related Genes in Sputum Cells in Asthma: Relationship to Demographic Features and Corticosteroids. Am J Respir Crit Care Med. 2020.

132. Johnston SL. Asthma and COVID-19: is asthma a risk factor for severe outcomes? Allergy. 2020.

133. Asthma GIf. COVID-19: GINA ANSWERS TO FREQUENTLY ASKED QUESTIONS ON ASTHMA MANAGEMENT. 2020; https://ginasthma.org/covid-19-gina-answers-to-frequently-askedquestions-on-asthma-management/. Accessed May 21, 2020. 
134. Kampf G, Todt D, Pfaender S, Steinmann E. Persistence of coronaviruses on inanimate surfaces and their inactivation with biocidal agents. J Hosp Infect. 2020;104(3):246-251.

135. Llewellin P, Sawyer G, Lewis S, et al. The relationship between FEV1 and PEF in the assessment of the severity of airways obstruction. Respirology. 2002;7(4):333-337.

136. Goyal M, Goel A, Bhattacharya S, Verma N, Tiwari S. Circadian variability in airways characteristics: A spirometric study. Chronobiol Int. 2019;36(11):1550-1557.

137. Matricardi PM, Dramburg S, Alvarez-Perea A, et al. The role of mobile health technologies in allergy care: An EAACI position paper.Allergy. 2020;75(2):259-272.

138. Morais-Almeida M, Aguiar R, Martin B, et al. COVID-19, asthma, and biologic therapies: What we need to know. World Allergy Organ J.2020:100126.

139. Chiappetta S, Sharma AM, Bottino V, Stier C. COVID-19 and the role of chronic inflammation in patients with obesity. Int J Obes (Lond). 2020.

140. Kruglikov IL, Scherer PE. The role of adipocytes and adipocyte-like cells in the severity of COVID-19 infections. Obesity (Silver Spring). 2020.

141. Kim HY, Lee HJ, Chang YJ, et al. Interleukin-17-producing innate lymphoid cells and the NLRP3 inflammasome facilitate obesity-associated airway hyperreactivity. Nat Med. 2014;20(1):54-61.

142. Grace J, Mohan A, Lugogo NL. Obesity and adult asthma: diagnostic and management challenges. Curr Opin Pulm Med. 2019;25(1):44-50.

143. Estebanez A, Perez-Santiago L, Silva E, Guillen-Climent S, Garcia-Vazquez A, Ramon MD. Cutaneous manifestations in COVID-19: a new contribution. J Eur Acad Dermatol Venereol. 2020.

144. Recalcati S. Cutaneous manifestations in COVID-19: a first perspective. J Eur Acad Dermatol Venereol. 2020;34(5):e212-e213.

145. Suchonwanit P, Leerunyakul K, Kositkuljorn C. Cutaneous manifestations in COVID-19: Lessons learned from current evidence.J Am Acad Dermatol. 2020.

146. Gelincik A BK, Çelik GE, Doña I, Mayorga L, Romano A, Soyer O, Atanaskovic-Markovic M, Barbaud A, Torres MJ. Diagnosis and management of the drug hypersensitivity reactions in Coronavirus disease 19. Allergy. 2020:(in press).

147. Wollenberg A, Flohr C, Simon D, et al. European Task Force on Atopic Dermatitis (ETFAD) statement on severe acute respiratory syndrome coronavirus 2 (SARS-Cov-2)-infection and atopic dermatitis. J Eur Acad Dermatol Venereol. 2020.

148. Meding B, Gronhagen CM, Bergstrom A, Kull I, Wrangsjo K, Liden C. Water Exposure on the Hands in Adolescents: A Report from the BAMSE Cohort. Acta Derm Venereol. 2017;97(2):188-192.

149. Prescott SL, Larcombe DL, Logan AC, et al. The skin microbiome: impact of modern environments on skin ecology, barrier integrity, and systemic immune programming. World Allergy Organ J.2017;10(1):29.

150. Yan Y, Chen H, Chen L, et al. Consensus of Chinese experts on protection of skin and mucous membrane barrier for health-care workers fighting against coronavirus disease 2019. Dermatol Ther.2020:e13310.

151. Carugno A, Raponi F, Locatelli AG, et al. No evidence of increased risk for COVID-19 infection in patients treated with Dupilumab for atopic dermatitis in a high-epidemic area - Bergamo, Lombardy, Italy. $J$ Eur Acad Dermatol Venereol. 2020.

152. Simpson EL, Paller AS, Siegfried EC, et al. Efficacy and Safety of Dupilumab in Adolescents With Uncontrolled Moderate to Severe Atopic Dermatitis: A Phase 3 Randomized Clinical Trial. JAMA Dermatol.2019. 
153. Schneeweiss MC, Perez-Chada L, Merola JF. Comparative Safety of Systemic Immuno-modulatory Medications in Adults with Atopic Dermatitis.J Am Acad Dermatol. 2019.

154. Blauvelt A, de Bruin-Weller M, Gooderham M, et al. Long-term management of moderate-to-severe atopic dermatitis with dupilumab and concomitant topical corticosteroids (LIBERTY AD CHRONOS): a 1-year, randomised, double-blinded, placebo-controlled, phase 3 trial.Lancet. 2017;389(10086):2287-2303.

155. Zhang Y, Cao W, Xiao M, et al. [Clinical and coagulation characteristics of 7 patients with critical COVID-2019 pneumonia and acro-ischemia]. Zhonghua Xue Ye Xue Za Zhi. 2020;41(0):E006.

156. Sanders JM, Monogue ML, Jodlowski TZ, Cutrell JB. Pharmacologic Treatments for Coronavirus Disease 2019 (COVID-19): A Review.JAMA. 2020.

157. Xu X, Ong YK, Wang Y. Role of adjunctive treatment strategies in COVID-19 and a review of international and national clinical guidelines. Mil Med Res. 2020;7(1):22.

158. Thachil J, Tang N, Gando S, et al. ISTH interim guidance on recognition and management of coagulopathy in COVID-19. J Thromb Haemost. 2020;18(5):1023-1026.

159. Stockman LJ, Bellamy R, Garner P. SARS: systematic review of treatment effects. PLoS Med. 2006;3(9):e343.

160. Yam LY, Lau AC, Lai FY, et al. Corticosteroid treatment of severe acute respiratory syndrome in Hong Kong. J Infect.2007;54(1):28-39.

161. Shang L, Zhao J, Hu Y, Du R, Cao B. On the use of corticosteroids for 2019-nCoV pneumonia. The Lancet. 2020;395(10225):683-684.

162. NIH. Coronavirus Disease 2019 (COVID-19)

Treatment Guidelines. 2020; https://www.covid19treatmentguidelines.nih.gov/. Accessed May 24, 2020.

163. Funck-Brentano C, Salem J-E. Chloroquine or hydroxychloroquine for COVID-19: why might they be hazardous? The Lancet. 2020.

164. Luo P, Liu Y, Qiu L, Liu X, Liu D, Li J. Tocilizumab treatment in COVID-19: A single center experience. J Med Virol. 2020.

165. Alberici F, Delbarba E, Manenti C, et al. A single center observational study of the clinical characteristics and short-term outcome of 20 kidney transplant patients admitted for SARS-CoV2 pneumonia. Kidney Int. 2020.

166. Capra R, De Rossi N, Mattioli F, et al. Impact of low dose tocilizumab on mortality rate in patients with COVID-19 related pneumonia. Eur J Intern Med. 2020.

167. Colaneri M, Bogliolo L, Valsecchi P, et al. Tocilizumab for Treatment of Severe COVID-19 Patients: Preliminary Results from SMAtteo COvid19 REgistry (SMACORE). Microorganisms. 2020;8(5).

168. Di Giambenedetto S, Ciccullo A, Borghetti A, et al. Off-label Use of Tocilizumab in Patients with SARS-CoV-2 Infection. J Med Virol. 2020.

169. Jacobs JP, Stammers AH, St Louis J, et al. Extracorporeal Membrane Oxygenation in the Treatment of Severe Pulmonary and Cardiac Compromise in COVID-19: Experience with 32 patients. ASAIO J. 2020.

170. Klopfenstein T, Zayet S, Lohse A, et al. Tocilizumab therapy reduced intensive care unit admissions and/or mortality in COVID-19 patients. Med Mal Infect. 2020.

171. Mazzitelli M, Arrighi E, Serapide F, et al. Use of subcutaneous tocilizumab in patients with COVID-19 pneumonia. J Med Virol.2020. 
172. Pereira MR, Mohan S, Cohen DJ, et al. COVID-19 in solid organ transplant recipients: Initial report from the US epicenter. Am J Transplant. 2020.

173. Piva S, Filippini M, Turla F, et al. Clinical presentation and initial management critically ill patients with severe acute respiratory syndrome coronavirus 2 (SARS-CoV-2) infection in Brescia, Italy. J Crit Care. 2020;58:29-33.

174. Sciascia S, Apra F, Baffa A, et al. Pilot prospective open, single-arm multicentre study on off-label use of tocilizumab in patients with severe COVID-19. Clin Exp Rheumatol. 2020.

175. Toniati P, Piva S, Cattalini M, et al. Tocilizumab for the treatment of severe COVID-19 pneumonia with hyperinflammatory syndrome and acute respiratory failure: A single center study of 100 patients in Brescia, Italy. Autoimmun Rev. 2020:102568.

176. Xu X, Han M, Li T, et al. Effective treatment of severe COVID-19 patients with tocilizumab. Proc Natl Acad Sci U S A.2020;117(20):10970-10975.

177. Xie M, Chen Q. Insight into 2019 novel coronavirus - An updated interim review and lessons from SARS-CoV and MERS-CoV. Int J Infect Dis. 2020;94:119-124.

178. Fang L, Karakiulakis G, Roth M. Are patients with hypertension and diabetes mellitus at increased risk for COVID-19 infection? Lancet Respir Med. 2020;8(4):e21.

179. Agency EM. EMA gives advice on the use of non-steroidal anti-inflammatories for COVID-19 2020; https://www.ema.europa.eu/en/news/ema-gives-advice-use-non-steroidal-anti-inflammatories-covid-19. Accessed May 20, 2020.

180. Bonini S, Maltese G. COVID-19Clinical trials: quality matters more than quantity. Allergy. 2020.

181. Zhou M, Zhang X, Qu J. Coronavirus disease 2019 (COVID-19): a clinical update. Front Med. 2020;14(2):126-135.

182. Mehra MR, Desai SS, Ruschitzka F, Patel AN. Hydroxychloroquine or chloroquine with or without a macrolide for treatment of COVID-19: a multinational registry analysis. The Lancet. 2020.

183. McKee DL, Sternberg A, Stange U, Laufer S, Naujokat C. Candidate drugs against SARS-CoV-2 and COVID-19. Pharmacol Res.2020;157:104859.

184. Bian H, Zheng Z-H, Wei D, et al. Meplazumab treats COVID-19 pneumonia: an open-labelled, concurrent controlled add-on clinical trial. medRxiv. 2020:2020.2003.2021.20040691.

185. Monteil V, Kwon H, Prado P, et al. Inhibition of SARS-CoV-2 Infections in Engineered Human Tissues Using Clinical-Grade Soluble Human ACE2. Cell. 2020;181(4):905-913 e907.

186. Grein J, Ohmagari N, Shin D, et al. Compassionate Use of Remdesivir for Patients with Severe Covid-19. $N$ Engl J Med. 2020.

187. Beigel JH, Tomashek KM, Dodd LE, et al. Remdesivir for the Treatment of Covid-19 - Preliminary Report. N Engl J Med. 2020.

188. Blanco JL, Ambrosioni J, Garcia F, et al. COVID-19 in patients with HIV: clinical case series. Lancet HIV. 2020;7(5):e314-e316.

189. Cao B, Wang Y, Wen D, et al. A Trial of Lopinavir-Ritonavir in Adults Hospitalized with Severe Covid-19. N Engl J Med.2020;382(19):1787-1799.

190. Ford N, Vitoria M, Rangaraj A, Norris SL, Calmy A, Doherty M. Systematic review of the efficacy and safety of antiretroviral drugs against SARS, MERS or COVID-19: initial assessment. J Int AIDS Soc. 2020;23(4):e25489. 
191. Duan K, Liu B, Li C, et al. Effectiveness of convalescent plasma therapy in severe COVID-19 patients. Proc Natl Acad Sci U S A.2020;117(17):9490-9496.

192. Stebbing J, Phelan A, Griffin I, et al. COVID-19: combining antiviral and anti-inflammatory treatments. Lancet Infect Dis.2020;20(4):400-402.

193. Cantini F, Niccoli L, Matarrese D, Nicastri E, Stobbione P, Goletti D. Baricitinib therapy in COVID-19: A pilot study on safety and clinical impact. J Infect. 2020.

194. Caly L, Druce JD, Catton MG, Jans DA, Wagstaff KM. The FDA-approved drug ivermectin inhibits the replication of SARS-CoV-2 in vitro. Antiviral Res. 2020;178:104787.

195. Schmith VD, Zhou JJ, Lohmer LR. The Approved Dose of Ivermectin Alone is not the Ideal Dose for the Treatment of COVID-19. Clin Pharmacol Ther. 2020.

196. Geleris J, Sun Y, Platt J, et al. Observational Study of Hydroxychloroquine in Hospitalized Patients with Covid-19. N Engl J Med. 2020.

197. Borba MGS, Val FFA, Sampaio VS, et al. Effect of High vs Low Doses of Chloroquine Diphosphate as Adjunctive Therapy for Patients Hospitalized With Severe Acute Respiratory Syndrome Coronavirus 2 (SARS-CoV-2) Infection: A Randomized Clinical Trial. JAMA Netw Open. 2020;3(4):e208857.

198. Magagnoli J, Narendran S, Pereira F, et al. Outcomes of hydroxychloroquine usage in United States veterans hospitalized with Covid-19. medRxiv. 2020:2020.2004.2016.20065920.

199. Khoury M, Cuenca J, Cruz FF, Figueroa FE, Rocco PRM, Weiss DJ. Current Status of Cell-Based Therapies for Respiratory Virus Infections: Applicability to COVID-19. Eur Respir J. 2020.

200. Zhang H, Penninger JM, Li Y, Zhong N, Slutsky AS. Angiotensin-converting enzyme 2 (ACE2) as a SARS-CoV-2 receptor: molecular mechanisms and potential therapeutic target. Intensive care medicine. 2020;46(4):586-590.

201. WHO. COVID-19 and the use of angiotensin-converting enzyme inhibitors and receptor blockers. 2020; https://www.who.int/news-room/commentaries/detail/covid-19-and-the-use-of-angiotensinconverting-enzyme-inhibitors-and-receptor-blockers. Accessed May 27, 2020.

202. Soldatov VO, Kubekina MV, Silaeva YY, Bruter AV, Deykin AV. On the way from SARS-CoV-sensitive mice to murine COVID-19 model. In: Pensoft Publishers; 2020.

203. Thanh Le T, Andreadakis Z, Kumar A, et al. The COVID-19 vaccine development landscape. Nat Rev Drug Discov. 2020;19(5):305-306.

204. WHO. DRAFT landscape of COVID-19 candidate vaccines 2020; https://www.who.int/docs/default-source/coronaviruse/novel-coronavirus-landscape-covid-

19fbda851295d245e48d8d0a78b35af7ff.pdf?sfvrsn=1720b348_1\&download=true. Accessed May 25, 2020.

205. Wrapp D, De Vlieger D, Corbett KS, et al. Structural Basis for Potent Neutralization of Betacoronaviruses by Single-Domain Camelid Antibodies. Cell. 2020.

206. Wang C, Li W, Drabek D, et al. A human monoclonal antibody blocking SARS-CoV-2 infection. Nat Commun. 2020;11(1):2251.

207. Larios Mora A, Detalle L, Gallup JM, et al. Delivery of ALX-0171 by inhalation greatly reduces respiratory syncytial virus disease in newborn lambs. MAbs. 2018;10(5):778-795.

208. Grgic H, Hunter DB, Hunton P, Nagy E. Vaccine efficacy against Ontario isolates of infectious bronchitis virus. Can J Vet Res.2009;73(3):212-216.

209. Zhu FC, Li YH, Guan XH, et al. Safety, tolerability, and immunogenicity of a recombinant adenovirus type- 5 vectored COVID-19 vaccine: a dose-escalation, open-label, non-randomised, first-in-human trial. 
Lancet. 2020.

210. Arons MM, Hatfield KM, Reddy SC, et al. Presymptomatic SARS-CoV-2 Infections and Transmission in a Skilled Nursing Facility. N Engl J Med. 2020.

211. Gandhi M, Yokoe DS, Havlir DV. Asymptomatic Transmission, the Achilles' Heel of Current Strategies to Control Covid-19. N Engl J Med. 2020.

212. Hains DS, Schwaderer AL, Carroll AE, et al. Asymptomatic Seroconversion of Immunoglobulins to SARS-CoV-2 in a Pediatric Dialysis Unit. JAMA. 2020.

213. McAnulty JM, Ward K. Suppressing the Epidemic in New South Wales.N Engl J Med. 2020;382(21):e74.

214. Fauci AS, Lane HC, Redfield RR. Covid-19 - Navigating the Uncharted. $N$ Engl J Med. 2020;382(13):1268-1269.

215. Petrosillo N, Viceconte G, Ergonul O, Ippolito G, Petersen E. COVID-19, SARS and MERS: are they closely related? Clin Microbiol Infect. 2020;26(6):729-734.

216. Lu X, Zhang L, Du H, et al. SARS-CoV-2 Infection in Children. N Engl J Med. 2020;382(17):1663-1665.

217. Dong Y, Mo X, Hu Y, et al. Epidemiology of COVID-19 Among Children in China. Pediatrics. 2020.

218. Parri N, Lenge M, Buonsenso D, Coronavirus Infection in Pediatric Emergency Departments Research G. Children with Covid-19 in Pediatric Emergency Departments in Italy. N Engl J Med. 2020.

219. Castagnoli R, Votto M, Licari A, et al. Severe Acute Respiratory Syndrome Coronavirus 2 (SARS-CoV2) Infection in Children and Adolescents: A Systematic Review. JAMA Pediatr. 2020.

220. Garazzino S, Montagnani C, Donà D, et al. Multicentre Italian study of SARS-CoV-2 infection in children and adolescents, preliminary data as at 10 April 2020. Eurosurveillance. 2020;25(18):2000600.

221. Johnston NW, Johnston SL, Norman GR, Dai J, Sears MR. The September epidemic of asthma hospitalization: school children as disease vectors.J Allergy Clin Immunol. 2006;117(3):557-562.

222. Shi J, Wen Z, Zhong G, et al. Susceptibility of ferrets, cats, dogs, and other domesticated animals to SARS-coronavirus 2.Science. 2020.

223. Livingston E, Bucher K. Coronavirus Disease 2019 (COVID-19) in Italy. JAMA. 2020.

224. Targher G, Mantovani A, Wang XB, et al. Patients with diabetes are at higher risk for severe illness from COVID-19. Diabetes Metab.2020.

225. Pareek M, Bangash MN, Pareek N, et al. Ethnicity and COVID-19: an urgent public health research priority. Lancet.2020;395(10234):1421-1422.

226. Khunti K, Singh AK, Pareek M, Hanif W. Is ethnicity linked to incidence or outcomes of covid-19? BMJ. 2020;369:m1548.

227. Millett GA, Jones AT, Benkeser D, et al. Assessing Differential Impacts of COVID-19 on Black Communities. Ann Epidemiol. 2020.

228. Forbes RL, Gibson PG, Murphy VE, Wark PA. Impaired type I and III interferon response to rhinovirus infection during pregnancy and asthma. Thorax. 2012;67(3):209-214.

229. Qiancheng X, Jian S, Lingling P, et al. Coronavirus disease 2019 in pregnancy. Int J Infect Dis. 2020;95:376-383.

230. Whitehead CL, Walker SP. Consider pregnancy in COVID-19 therapeutic drug and vaccine trials. Lancet. 2020;395(10237):e92. 
231. Gielen V, Johnston SL, Edwards MR. Azithromycin induces anti-viral responses in bronchial epithelial cells. Eur Respir J.2010;36(3):646-654.

232. Chico RM, Chandramohan D. Azithromycin plus chloroquine: combination therapy for protection against malaria and sexually transmitted infections in pregnancy. Expert Opin Drug Metab Toxicol. 2011;7(9):1153-1167.

233. Bacharier LB, Guilbert TW, Mauger DT, et al. Early Administration of Azithromycin and Prevention of Severe Lower Respiratory Tract Illnesses in Preschool Children With a History of Such Illnesses: A Randomized Clinical Trial. JAMA. 2015;314(19):2034-2044.

234. Gibson PG, Yang IA, Upham JW, et al. Effect of azithromycin on asthma exacerbations and quality of life in adults with persistent uncontrolled asthma (AMAZES): a randomised, double-blind, placebo-controlled trial. Lancet. 2017;390(10095):659-668.

235. Gibson WT, Evans DM, An J, Jones SJM. ACE 2 Coding Variants: A Potential X-linked Risk Factor for COVID-19 Disease. bioRxiv.2020:2020.2004.2005.026633.

236. Berghofer B, Frommer T, Haley G, Fink L, Bein G, Hackstein H. TLR7 ligands induce higher IFN-alpha production in females. J Immunol.2006;177(4):2088-2096.

237. Grasselli G, Zangrillo A, Zanella A, et al. Baseline Characteristics and Outcomes of 1591 Patients Infected With SARS-CoV-2 Admitted to ICUs of the Lombardy Region, Italy. JAMA. 2020.

238. Li X, Xu S, Yu M, et al. Risk factors for severity and mortality in adult COVID-19 inpatients in Wuhan. J Allergy Clin Immunol. 2020.

239. Gudbjartsson DF, Helgason A, Jonsson H, et al. Spread of SARS-CoV-2 in the Icelandic Population. $N$ Engl J Med. 2020.

240. CDC. Weekly Updates by Select Demographic and Geographic Characteristics. 2020; https://www.cdc.gov/nchs/nvss/vsrr/covid_weekly/index.htm\#AgeAndSex. Accessed May 27, 2020.

241. Xie J, Tong Z, Guan X, Du B, Qiu H. Clinical Characteristics of Patients Who Died of Coronavirus Disease 2019 in China. JAMA Netw Open. 2020;3(4):e205619.

242. McMichael TM, Currie DW, Clark S, et al. Epidemiology of Covid-19 in a Long-Term Care Facility in King County, Washington. N Engl J Med. 2020;382(21):2005-2011.

243. Linka K, Peirlinck M, Sahli Costabal F, Kuhl E. Outbreak dynamics of COVID-19 in Europe and the effect of travel restrictions. Comput Methods Biomech Biomed Engin. 2020:1-8.

244. Shaman J, Goldstein E, Lipsitch M. Absolute humidity and pandemic versus epidemic influenza. Am J Epidemiol. 2011;173(2):127-135.

245. Miller MA, Viboud C, Balinska M, Simonsen L. The signature features of influenza pandemicsimplications for policy. $N$ Engl J Med.2009;360(25):2595-2598.

246. Neher RA, Dyrdak R, Druelle V, Hodcroft EB, Albert J. Potential impact of seasonal forcing on a SARS-CoV-2 pandemic. Swiss Med Wkly. 2020;150:w20224.

247. Hamner L, Dubbel P, Capron I, et al. High SARS-CoV-2 Attack Rate Following Exposure at a Choir Practice - Skagit County, Washington, March 2020. MMWR Morb Mortal Wkly Rep. 2020;69(19):606-610.

248. Wilson NM, Norton A, Young FP, Collins DW. Airborne transmission of severe acute respiratory syndrome coronavirus-2 to healthcare workers: a narrative review. Anaesthesia. 2020.

249. Liu Y, Ning Z, Chen Y, et al. Aerodynamic analysis of SARS-CoV-2 in two Wuhan hospitals. Nature. 2020 . 
250. Zhang J, Litvinova M, Liang Y, et al. Changes in contact patterns shape the dynamics of the COVID-19 outbreak in China. Science.2020:eabb8001.

251. Matrajt L, Leung T. Evaluating the Effectiveness of Social Distancing Interventions to Delay or Flatten the Epidemic Curve of Coronavirus Disease. Emerg Infect Dis. 2020;26(8).

252. Epidemiology Working Group for Ncip Epidemic Response CCfDC, Prevention. [The epidemiological characteristics of an outbreak of 2019 novel coronavirus diseases (COVID-19) in China]. Zhonghua Liu Xing Bing Xue Za Zhi. 2020;41(2):145-151.

253. van Doremalen N, Bushmaker T, Morris DH, et al. Aerosol and Surface Stability of SARS-CoV-2 as Compared with SARS-CoV-1. N Engl J Med. 2020;382(16):1564-1567.

254. Chen J, Qi T, Liu L, et al. Clinical progression of patients with COVID-19 in Shanghai, China. J Infect. 2020;80(5):e1-e6.

255. Jartti T, Palomares O, Waris M, et al. Distinct regulation of tonsillar immune response in virus infection. Allergy.2014;69(5):658-667.

256. Cai Q, Huang D, Ou P, et al. COVID-19 in a designated infectious diseases hospital outside Hubei Province, China. Allergy.2020;n/a(n/a).

257. Riou J, Althaus CL. Pattern of early human-to-human transmission of Wuhan 2019 novel coronavirus (2019-nCoV), December 2019 to January 2020. Euro Surveill. 2020;25(4).

258. Endo A, Abbott S, Kucharski AJ, Funk S. Estimating the overdispersion in COVID-19 transmission using outbreak sizes outside China. Wellcome Open Research. 2020;5(67).

259. Studdert DM, Hall MA. Disease Control, Civil Liberties, and Mass Testing - Calibrating Restrictions during the Covid-19 Pandemic. N Engl J Med. 2020.

260. Ng Y, Li Z, Chua YX, et al. Evaluation of the Effectiveness of Surveillance and Containment Measures for the First 100 Patients with COVID-19 in Singapore - January 2-February 29, 2020. MMWR Morb Mortal Wkly Rep. 2020;69(11):307-311.

261. Guo Y, Li Y, Monroe-Wise A, Yeung SJ, Huang Y. A dynamic residential community-based quarantine strategy: China's experience in fighting COVID-19. Infect Control Hosp Epidemiol. 2020:1.

262. Licari A, Votto M, Brambilla I, et al. Allergy and asthma in children and adolescents during the COVID outbreak: what we know and how we could prevent allergy and asthma flares? Allergy. n/a(n/a).

263. Sotgiu G, Gerli AG, Centanni S, et al. Advanced forecasting of SARS-CoV-2-related deaths in Italy, Germany, Spain, and New York State.Allergy. 2020;n/a(n/a).

264. Yasaka TM, Lehrich BM, Sahyouni R. Peer-to-Peer Contact Tracing: Development of a PrivacyPreserving Smartphone App. JMIR Mhealth Uhealth. 2020;8(4):e18936.

265. Parker MJ, Fraser C, Abeler-Dorner L, Bonsall D. Ethics of instantaneous contact tracing using mobile phone apps in the control of the COVID-19 pandemic. J Med Ethics. 2020.

266. Stampfli MR, Anderson GP. How cigarette smoke skews immune responses to promote infection, lung disease and cancer. Nat Rev Immunol. 2009;9(5):377-384.

267. Patanavanich R, Glantz SA. Smoking is Associated with COVID-19 Progression: A Meta-Analysis. medRxiv.2020:2020.2004.2013.20063669.

268. Szabo G, Saha B. Alcohol's Effect on Host Defense. Alcohol Res. 2015;37(2):159-170.

269. Pang M, Bala S, Kodys K, Catalano D, Szabo G. Inhibition of TLR8- and TLR4-induced Type I IFN induction by alcohol is different from its effects on inflammatory cytokine production in monocytes. $B M C$ Immunol. 2011;12:55. 
270. Simonnet A, Chetboun M, Poissy J, et al. High prevalence of obesity in severe acute respiratory syndrome coronavirus-2 (SARS-CoV-2) requiring invasive mechanical ventilation. Obesity (Silver Spring). 2020.

271. Campagna M, Rivas C. Antiviral activity of resveratrol.Biochem Soc Trans. 2010;38(Pt 1):50-53.

272. Ellenbogen Y, Jimenez-Saiz R, Spill P, Chu DK, Waserman S, Jordana M. The Initiation of Th2 Immunity Towards Food Allergens. Int J Mol Sci. 2018;19(5).

273. Jimenez-Saiz R, Ellenbogen Y, Koenig JFE, et al. IgG1(+) B-cell immunity predates IgE responses in epicutaneous sensitization to foods. Allergy. 2019;74(1):165-175.

274. Wang M, Tan G, Eljaszewicz A, et al. Laundry detergents and detergent residue after rinsing directly disrupt tight junction barrier integrity in human bronchial epithelial cells. J Allergy Clin Immunol. 2019;143(5):1892-1903.

275. Agache I, Miller R, Gern JE, et al. Emerging concepts and challenges in implementing the exposome paradigm in allergic diseases and asthma: a Practall document. Allergy. 2019;74(3):449-463.

276. Garcia-Alvarez L, Fuente-Tomas L, Saiz PA, Garcia-Portilla MP, Bobes J. Will changes in alcohol and tobacco use be seen during the COVID-19 lockdown? Adicciones. 2020;32(2):85-89.

277. Shen C, Wang Z, Zhao F, et al. Treatment of 5 Critically Ill Patients With COVID-19 With Convalescent Plasma. JAMA. 2020.

278. Zhang B, Liu S, Tan T, et al. Treatment With Convalescent Plasma for Critically Ill Patients With Severe Acute Respiratory Syndrome Coronavirus 2 Infection. Chest. 2020.

279. Ahn JY, Sohn Y, Lee SH, et al. Use of Convalescent Plasma Therapy in Two COVID-19 Patients with Acute Respiratory Distress Syndrome in Korea. J Korean Med Sci. 2020;35(14):e149.

280. Ye M, Fu D, Ren Y, et al. Treatment with convalescent plasma for COVID-19 patients in Wuhan, China. J Med Virol. 2020;n/a(n/a).

281. Zeng QL, Yu ZJ, Gou JJ, et al. Effect of Convalescent Plasma Therapy on Viral Shedding and Survival in COVID-19 Patients. J Infect Dis. 2020. 